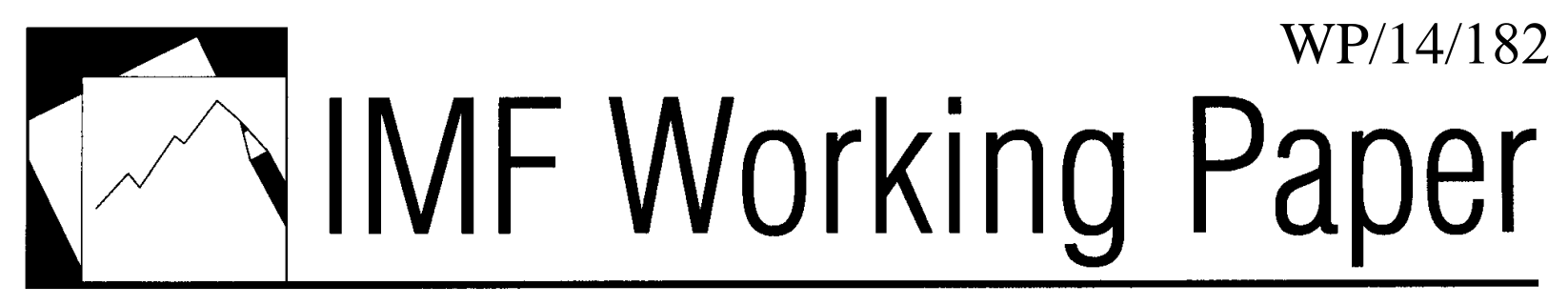

\title{
Food Prices and the Multiplier Effect of Trade Policy
}

\author{
Paolo Giordani, Nadia Rocha \& Michele Ruta
}




\title{
Food Prices and the Multiplier Effect of Trade Policy*
}

\author{
Paolo E. Giordani \\ LUISS "Guido Carli" University World Trade Organization \\ Michele Ruta \\ International Monetary Fund
}

September 2014

\begin{abstract}
This paper studies the relationship between trade policy and food prices. We show that, when individuals are loss averse, governments may use trade policy to shield the domestic economy from large food price shocks. This creates a complementarity between the price of food in international markets and trade policy. Specifically, unilateral actions give rise to a "multiplier effect": when a shock drives up the price of food, exporters respond by imposing restrictions while importers wind down protection, thus exacerbating the initial shock and soliciting further trade policy activism. We test the key prediction of the theory with a new dataset that comprises monthly information on trade measures across 77 countries and 33 food products for the period 2008-11, finding evidence of a multiplier effect in food trade policy. These findings contribute to inform the broader debate on the proper regulation of food trade policy within the multilateral trading system.
\end{abstract}

Keywords: Loss aversion; Trade policy; Multiplier effect; Food crisis.

JEL Classification: F13, F59, Q02, Q17.

*A previous version of this paper circulated with the title "Food prices and the multiplier effect of export policy". We would like to thank Robert Staiger and two anonymous referees for in-depth comments. We are also grateful to Willy Alfaro, Simon Evenett, Gabriel Felbermayr, Caroline Freund, Robert Gulotty, Lee Ann Jackson, Nuno Limao, Marcelo Olarreaga, Gianluca Orefice, Roberta Piermartini, Frederic Robert-Nicoud and seminar participants at Johns Hopkins (SAIS), WTO, ETSG, LUISS, University of Munich, University of Frankfurt, and the IMF/WB/WTO Trade Workshop for helpful discussions. Joelle Latina provided excellent research assistance. Remaining errors are our responsibility. Michele Ruta gratefully acknowledges hospitality at the International Trade Department of CES-ifo during the early stages of this research project. Disclaimer: The opinions expressed in this paper should be attributed to the authors. They are not meant to represent the positions or opinions of the IMF or the WTO and their Members. 


\section{Introduction}

International food prices have been a key policy concern in recent years. Figure 1 illustrates the extent to which the periods 2006-2008 and 2008-2011 differ from the preceding two decades, justifying the labeling of "food crises". While a number of factors may have contributed to the sudden and rapid spikes in food prices (e.g. reduction in key food stocks, increasing demand in emerging economies, financial speculation, changes in monetary policy in leading economies), several observers have pointed out that trade policy may be part of the problem of escalating prices. ${ }^{1}$ Figure 2 corroborates this view by showing a positive correlation between the use of trade policy in the food sector (the number of export restrictions and import tariff and quota reductions) and the global price of food between 2008 and 2011. This motivates our key research question: how does trade policy interact with food prices? Any proposal of reform of the current rules on agricultural trade policy within the multilateral trading system needs to depart from a better understanding of this relationship.

Our view can be very simply stated. When trade policy aims at shielding the domestic market from unfavorable developments in the world market, export and import measures have a "multiplier effect". Specifically, high prices of food may trigger a series of measures aimed at restricting exports in food exporting countries and promoting imports in food importing economies. Similarly, low prices of food may lead exporting governments to raise export promotion measures and importing countries to tighten import restrictions. These policies shift the world export supply and import demand of food, thus exacerbating tensions in the world food market and feeding into a new round of trade measures. This paper presents a micro-founded model of this interaction between trade policy and food prices (both under the case of small and of large exporting economies) and tests its main prediction with trade policy data for the period 2008-11.

The theory builds on recent developments in the literature on behavioral economics and trade policy (Freund and Ozden, 2008, and Tovar, 2009). This literature modifies an otherwise standard trade policy model to account for the empirical fact that individuals value losses more than gains (loss aversion). In this setting, preventing losses may loom large in the government's objective function. We show that when the world food market is hit by a negative price shock, food producers experience a welfare loss. A welfare maximizing government will offset this loss by offering an export subsidy / import tariff if the shock is sufficiently large (i.e. the domestic food price falls below a reference point for producers). On the contrary, when the world food market is hit by a positive price shock, consumers face a loss and the government responds by imposing an export tax / import subsidy when the shock is sufficiently large (i.e. the domestic food price rises above a reference point for consumers). Finally, when global food prices are at intermediate levels, there is no rationale for government intervention to prevent losses and policy makers face the standard incentives in setting trade policy.

A model with loss aversion is not the only framework under which (unilaterally optimal) trade policy is a function of the international price of food. For instance, Gouel and Jean (2013) show that consumers' risk aversion may provide a rationale for trade policy activism in presence of high and volatile world food prices. However, as argued in Anderson and Martin (2011), the trade policy behavior arising from a model based on loss aversion is consistent with the observed conduct of several

\footnotetext{
${ }^{1}$ A partial list includes Anderson and Martin (2011), Chaffour (2008), Bouet and Laborde (2012), Hochman et al. (2010), Headey (2011).
} 
governments. ${ }^{2}$ In particular, when agents are loss averse, the effect of world prices on consumer or producer welfare is non-linear, in the sense that it is triggered only when a shock pushes the food price beyond a reference point. This insight is key to understand the pattern of the trade policy response to food prices and the aggregate consequences of these measures.

Small countries take world prices as given and have, individually, no impact on global markets. However, as they all face the same international price of food and have similar incentives to insulate the domestic food market in presence of loss aversion, their simultaneous behavior will have aggregate consequences. In particular, we show that trade policy actions can give rise to a multiplier effect. Focus on a large positive food price shock (but the same logic applies to a negative shock). Exporters set export restrictions and importers increase import promotion to offset the world price increase and avoid consumer losses. Because all countries act, however, the world price of food rises even further (world export supply shifts in, while import demand shifts out), which makes the initial policy response inadequate to compensate consumers. The higher food price induces further restrictions by exporters and promotions by importers as governments strive to maintain a stable domestic price. Note that, differently from the initial response, further policy actions are not driven by fundamentals, but are only a reaction to the measures imposed by other governments. This is precisely the idea behind the multiplier effect.

The logic just discussed extends to the case where countries' policy decisions have an impact on global markets. Contrary to small economies, large exporters and importers do not take the international price of food as given and choose their trade policy strategically. In this context, when loss aversion looms large in the governments' objective function, trade policies are strategic complements. Intuitively, if a large exporter / importer raises its export tax / import subsidy, it increases the world price of food, which in turn leads other governments to further restrict their exports or subsidize their imports to avoid consumers' losses. This strategic complementarity of large economies' trade policy creates a multiplier effect that magnifies the consequences of exogenous shocks to the international price of food. Mutatis mutandis, the logic holds true for export subsidies by large exporters and import tariffs by large importers.

We empirically test the key prediction of the model, the existence of a multiplier effect in food trade policy, for the years 2008-11. During this period, food prices were over 80 per cent higher than average prices between 1990 and 2006 with peaks of over 100 percent for certain staple foods such as cereals. At the same time, governments have widely used trade policy instruments to restrict exports and promote imports of food products: a total of 281 measures were recorded between 2008 and 2011 . Our empirical strategy has two components. First, we examine the determinants of trade measures in the food sector. In particular, we investigate the impact of international price movements from their reference value and of global trade policy utilization on the probability of imposing a trade measure. Second, we estimate a simultaneous equation model to assess the overall impact of trade policy on food prices.

In order to deal with the endogeneity of our explanatory variables, we follow an instrumental variables approach. We use the level and variability of rainfall precipitation in top producing countries of a certain food product to instrument its world price. High levels and high variability of rainfall are negatively related with food production and, therefore, have a positive impact on world food

\footnotetext{
${ }^{2}$ See also the discussion in Ivanic et al. (2011).
} 
prices through a supply channel. This is particularly relevant for staple products such as cereals and other staple crops than for processed foods. For global trade policy utilization in a product, we use as instruments the electoral cycle for top traders and the total number of measures in the two-digit industry to which the product belongs. Our claim is that governments are more prone to use trade measures that hurt producers when there are no elections looming and as a result of a simulation effect of policies imposed on similar products.

We use a new data set on trade policy measures from the WTO Monitoring exercise and complement it with additional information from the Global Trade Alert. This dataset contains monthly information on the state of export and import restrictions in the food sector across 77 countries at the 4-digit level. We measure global trade policy utilization in the food sector with the share of international trade covered by increases in export restrictions and reductions in import protections. These trade shares vary substantially in our sample, ranging from close to zero for bananas to 36 per cent for rice and 74 per cent for wheat and meslin. In the whole food sector, on average 8 per cent of trade is covered by export restrictions and tariff and quota reductions. When we focus on important food products such as staple foods, global trade policy utilization is substantially higher in the period of observation (16 per cent on average).

The empirical results strongly support the predictions of the model. First, we construct a theoryconsistent measure of food price changes (using different approaches to formulate the reference price) and find that governments set trade policy in response to these deviations. Second, we find that the extent of global trade policy utilization on a product has a positive and significant impact on the probability that a government has a higher restriction to the exports of that product or a lower protection to its import. We also show that these findings are robust to several specifications and to potential endogeneity problems. Finally, results from the simultaneous equations estimation show that global trade policy utilization has considerably increased world prices of staple foods in 2008-11. On average, a 1 per cent surge in the share of trade covered by export restrictions and import promotions is associated to an increase in international staple food prices between 0.4 and 2.1 per cent. These findings support the view that trade policy was an important contributing factor to the global food crisis in 2008-11.

There is a wide body of related literature that deals with trade policy in the agricultural sector and we do not attempt to summarize it here. Closer to our paper are the works by Anderson and Martin (2011) and Bouet and Laborde (2012). They share the view that trade policy in the food sector can aim at insulating the domestic market and that these policy actions may contribute to disrupt international food markets. Our study differs from these works for two main reasons. First, we provide a fully micro-founded model and analytically prove the existence of a multiplier effect in trade policy. Second, our empirical analysis uses actual information on trade policy measures rather than indirect estimates based on agricultural distortions in selected food sectors (Anderson and Martin, 2011) or simulations (Bouet and Laborde, 2012). In brief, our results complement and provide further support to previous studies.

Our work also relates to the literature that deals with the efficient design of trade agreements (Bagwell and Staiger, 2002) and the rationale for trade policy rules in the agricultural sector (Bagwell and Staiger, 2001). This literature identifies in the terms-of-trade manipulation the main problem that trade agreements are trying to solve and attempts to understand and interpret the key design 
issues of the multilateral trading system in light of this rationale. The scope of our paper is more limited, but complementary to this line of work. We show that in the food sector, governments' trade policy decisions may at times be driven by a rationale different from terms-of-trade manipulation (i.e. avoiding large consumer or producer losses) and that this behavior may help explain food price volatility in international markets through the mechanism of the multiplier effect. While our work may provide useful information to address questions of institutional design, we do not pursue such questions here.

The paper is structured as follows. Section 2 presents the model of trade policy under loss aversion and uses this framework to show the existence of a multiplier effect in food trade policy. Section 3 studies the empirical relevance of this prediction using price and trade policy information for the period 2008-2011. Concluding remarks follow. All the proofs are relegated to a technical appendix.

\section{$2 \quad$ Trade policy and food prices}

\subsection{The model: Food prices and loss aversion}

Consider a small open economy producing two goods, a numeraire and a commodity that we refer to as food. The economy may import/export the numeraire good at a unitary world price and export/import food at the world price, $p^{*}$. The numeraire is produced with labor alone, using a constant returns to scale technology $\left(y_{0}=l_{0}\right)$. Assuming that labor supply is sufficiently large, the wage rate in the economy is fixed and equal to one. Food is produced using labor and a specific factor in fixed supply, land $(L)$. Technology in the food sector also exhibits constant returns to scale and takes the form $y=f(l, L)$. Given the domestic price of food, $p$, the return to the owners of the specific factor is $\pi(p)=\max _{l}[p f(l, L)-l]$. Finally, the domestic output of food is $y(p)=\pi^{\prime}(p)$.

The economy is composed of a continuum of individuals of measure one with identical preferences. We assume that agents derive utility from consumption of the two goods and from deviations from their reference-dependent utility. Specifically, the utility function has the following separable form:

$$
U=c_{0}+u(c)-I \cdot h\left(\bar{U}-c_{0}-u(c)\right)
$$

where $c_{0}$ is the consumption of the numeraire good and $c$ is food consumption. Function $u(\cdot)$ has the standard properties $\left(u^{\prime}(\cdot)>0, u^{\prime \prime}(\cdot)<0\right)$. Function $h(\cdot)$ captures the behavioral features of the model. In particular, $h(\cdot)$ is increasing in the difference between a reference level $\bar{U}$ and the actual utility from consumption (i.e. $h^{\prime}(\cdot)>0$ ), and it displays diminishing sensitivity to losses (i.e. $\left.h^{\prime \prime}(\cdot)<0\right)$. I is an indicator variable that takes value one whenever the utility falls strictly below the reference level and zero otherwise. This utility structure supports the idea that individuals experience a welfare loss when they achieve a level of utility inferior to what they are accustomed to, but do not perceive any additional welfare gain when utility is higher than usual. ${ }^{3}$ Since one of the two goods in this economy

\footnotetext{
${ }^{3}$ Freund and Ozden (2008) and Tovar (2009) have introduced loss aversion in a model of trade policy and find that this behavioral extension explains several features of the observed pattern of trade protectionism. Classic works on reference-dependent utility include Kahneman and Tversky (1979), Tversky and Kahneman (1991), and Koszegi and Rabin (2006). Moreover, Tversky and Kahneman (1981), Samuelson and Zeckhauser (1988), and Camerer (1995), among others, provide experimental evidence supporting this preference structure.
} 
is food, it is tempting to associate the reference utility $\bar{U}$ to a subsistence level of consumption, which may be considered unacceptably low and might justify policy intervention.

Maximizing utility given by (1) subject to the budget constraint gives the individual demand function of food $d(p)=\left[u^{\prime}(c)\right]^{-1}$, while remaining income is spent on the numeraire good, $c_{0}=$ $E-p d(p)$, where $E$ is individual income level. The government can intervene in the food sector via trade policy. ${ }^{4}$ Specifically, the government uses trade policy to create a wedge between the international and the domestic price of food, $p=p^{*}-t$. If it aims at protecting consumers, then $t$ is positive and represents an export tax or an import subsidy. If it aims at protecting producers, then $t$ is negative and represents an export subsidy or an import tariff. Government revenue is, therefore, given by

$$
G R(p)=\left(p^{*}-p\right)[y(p)-d(p)] \gtrless 0 .
$$

We assume that, whenever positive, the government redistributes revenue uniformly to all agents, while lump-sum taxes are used to finance a negative budget.

We denote by $\alpha$ the fraction of the population that owns land and call them land owners/producers. Agents in the remaining share of the population $(1-\alpha)$ have one unit of labor each that they supply inelastically to the market. We refer to this latter group as workers/consumers. In this setting, interests in society are radically different, as a change in the price of food affects different social groups in opposite ways. Intuitively, owners of land see their income and welfare positively tied to the domestic price of food, while workers are hurt by a surge in food prices as this limits their consumption possibilities. A fall in the domestic price of food has the opposite effect on the utility of these two social groups. Formally, the indirect utility of a worker and of a land owner can be written respectively as

$$
V_{\bar{p}}^{l}(p)=1+C S(p)+G R(p)-I^{l} \cdot h\left[V^{l}(\bar{p})-1-C S(p)-G R(p)\right]
$$

and

$$
V_{\underline{p}}^{L}(p)=\frac{\pi(p)}{\alpha}+C S(p)+G R(p)-I^{L} \cdot h\left[V^{L}(\underline{p})-\frac{\pi(p)}{\alpha}-C S(p)-G R(p)\right],
$$

where $C S(p)=u[d(p)]-p d(p)$ is consumer surplus. The indicator variable $I^{l}$ is equal to 1 whenever $V^{l}(\bar{p})>1+G R(p)+C S(p)$ and zero otherwise. The indicator variable $I^{L}$ is equal to 1 whenever $V^{L}(\underline{p})>\pi(p) / \alpha+G R(p)+C S(p)$ and zero otherwise.

As labor income is constant, the extent of loss aversion for workers is determined by consumer surplus and government revenue. Since the sum of these terms is strictly decreasing in $p$, their reservation utility corresponds to a unique reference price denoted by $\bar{p}$. More precisely, according to condition (3), whenever domestic food prices are high $(p>\bar{p})$, expected utility falls below the reference point, and workers/consumers incur an additional welfare loss captured by the term $h(\cdot)$. When instead food prices are low $(p<\bar{p})$, they do not derive any additional utility.

\footnotetext{
${ }^{4}$ As confirmed by the evidence provided in this paper and in the studies discussed in the Introduction, governments do indeed actively use trade policy in food sectors. An important question, not addressed in this paper, is why governments use more distorsive policies, such as trade policy, rather than more efficient tools, such as domestic measures. One reason may have to do with the availability of appropriate domestic policies, particularly in developing countries. Limao and Tovar (2011) provide an alternative explanation based on a political economy argument.
} 
On the other hand, assuming that land owners are a sufficiently small fraction $\alpha$ of the total population, they enjoy only a tiny share of the surplus generated by food consumption and perceive a negligible fraction of the tax revenue (or cost). For individuals in this group, an increase in the domestic price of food strictly increases utility, as the positive effect on the rent from the specific factor dominates the loss in consumer surplus and government revenue. As a result, the reference utility for producers corresponds to the unique price $\underline{p}$. According to condition (4), whenever the domestic price of food falls below this threshold level $(p<\underline{p})$, they perceive a decline in their welfare, but no additional welfare gain is incurred when land owners face a price of food higher than their reservation price. $^{5}$

\subsection{Unilateral food trade policy under loss aversion}

This section explores the optimal trade policy for a small open economy under loss aversion (Subsection 2.4 presents an extension to this basic framework where the economy is large in the international food market). Total welfare is defined as

$$
G(p)=W(p)+H(p),
$$

where standard social welfare (i.e., net of loss aversion) is the sum of labor income, revenue from the specific factor, consumer surplus and government revenue

$$
W(p)=(1-\alpha)+\pi(p)+C S(p)+G R(p),
$$

while loss aversion for the entire economy is

$$
H(p)=-(1-\alpha) I^{l} \cdot h\left[V^{l}(\bar{p})-1-C S(p)-G R(p)\right]-\alpha I^{L} \cdot h\left[V^{L}(\underline{p})-\frac{\pi(p)}{\alpha}-C S(p)-G R(p)\right] .
$$

The government sets trade policy to maximize social welfare given by condition (5). In this framework where loss aversion affects welfare, there are several different scenarios that need to be considered which depend on the level of the international price of food. In particular, there are three main regions. A first area corresponds to the situation where the international price of food has "intermediate" values, that is, when $p^{*} \in[\underline{p}, \bar{p}]$. In this case, the loss aversion term is null and the optimal trade policy is the one that corresponds to free trade. ${ }^{6}$ When the international price is "low"

\footnotetext{
${ }^{5}$ To be clear, this model introduces a different feature relative to Freund and Ozden (2008) and Tovar (2009). These authors abstract from the effect that changes in prices have on consumer surplus and government revenue and focus instead on the direct effect that these price changes have on the income of factor owners. This is a reasonable assumption in their models where there are many consumption goods, none of which is supposed to represent a large share of total consumption. The structure presented here is instead better suited to capture the fact that the poor, particularly in developing countries, spend an important portion of their income on food. For example, the poorest decile of the population in Nigeria, Vietnam and Indonesia spend respectively 70, 75, and 50 per cent of their income on food (Ivanic et al., 2011).

${ }^{6}$ The proofs of this and the following statements, which form the basis of Proposition 1 below, are provided in footnote as they are generalizations of results established in previous literature. The proofs of our novel results (Propositions 2, 3 and 4$)$ are in appendix. When $H(\cdot)=0$, total welfare reduces to the standard form: $G(p)=W(p)=(1-\alpha)+\pi(p)+$ $C S(p)+G R(p)$. The optimal domestic price is determined by the first order condition $\partial W / \partial p=\left(p^{*}-p\right)\left[y^{\prime}-d^{\prime}\right]=0$, which is satisfied for $p=p^{*}$.
} 
(i.e. $p^{*}<\underline{p}$ ) and when it is "high" (i.e. $p^{*}>\bar{p}$ ), the derivation of the optimal policy for a small open economy is more complicated, as either land owners/producers or workers/consumers suffer an additional welfare loss (i.e. $H(\cdot) \neq 0$ ).

Consider first the case where the international price of food is below the lower-bound of the reservation price, $\underline{p}$ (this is the case considered in previous literature). It can be shown that there exists a region of compensating protectionism, where the government, depending on whether it is a food exporter or importer, sets an export subsidy or an import tariff to fully compensate producers for the welfare loss caused by the fall in the international price of food. In fact, the first-order condition (FOC) of social welfare (5) with respect to the domestic price, which takes into account that in this scenario land owners experience a loss $\left(I^{L}=1\right)$, may or may not be satisfied in the region $\left(p^{*}, \underline{p}\right)$. Specifically, there is a critical level of the international price (call it $\left.\underline{p}^{c}<\underline{p}\right)$ such that, for $p^{*} \in\left(\underline{p}^{c}, \underline{p}\right)$, the FOC is not satisfied in the relevant region, and we have a corner solution. ${ }^{7}$ In this case, the government sets trade policy so that the domestic price equals $\underline{p}$, and the optimal policy (either an export subsidy or an import tariff) is

$$
t=p^{*}-\underline{p}<0
$$

If $p^{*} \leq \underline{p}^{c}$, the maximum is an interior solution. The government still imposes an export subsidy or an import tariff, but in this case it does not fully compensate producers. ${ }^{8}$

Consider next the scenario in which the international price of food is high, that is, where the price is above the reservation price of workers/consumers, $\bar{p}$. Similarly to the previous scenario, it can be shown that there exists a second region of compensating protectionism, where the policy maker imposes an export tax or an import subsidy to fully offset the welfare loss of consumers due to the increase in the world price of food. The FOC of social welfare with respect to the domestic price of food, which takes into account the additional welfare loss for workers $\left(I^{l}=1\right)$, may or may not be satisfied in the region $\left(\bar{p}, p^{*}\right)$, depending on whether the international price of food is below or above a threshold level, denoted by $\bar{p}^{c}>\bar{p}$. In particular, when $p^{*} \in\left(\bar{p}, \bar{p}^{c}\right)$, the FOC is not satisfied in the relevant region, and the government sets trade policy to maintain the domestic price of food at the

7 The FOC can be expressed as

$$
\frac{\partial G}{\partial p}=W^{\prime}+H^{\prime}=\left(p^{*}-p\right) x^{\prime}+\left[(1-\alpha) y+\alpha\left(p^{*}-p\right) x^{\prime}\right] \cdot h^{\prime}=0,
$$

where $x(p)=y(p)-d(p)$ is net export supply (or import demand if negative) of food. Consider the case in which the international price falls from $p^{*}=\underline{p}$ to $p^{*}=\underline{p}-\varepsilon$. For $\varepsilon$ small enough, $W^{\prime}(\underline{p}-\varepsilon)=0$, while $H^{\prime}(\underline{p}-\varepsilon)>0$, which implies $G^{\prime}(\underline{p}-\varepsilon)>0$. In this case, the optimal domestic price of food is a corner solution and is equal to the reservation price for land owners, $\underline{p}$. As $\varepsilon$ increases (and, hence, $p^{*}$ moves away from $\underline{p}$ ), the loss aversion effect weakens due to diminishing sensitivity to losses $\left(h^{\prime \prime}<0\right)$, while $W^{\prime}(\underline{p})$ becomes more negative. This implies that there is a critical level of the world price $p^{*}=p^{c}<p$, below which the optimal domestic price is an interior solution to the welfare maximizing problem.

${ }^{8}$ In particular, solving the FOC when $H(\cdot) \neq 0$ gives the following export subsidy (import tariff):

$$
\frac{-t}{p^{*}-t}=\frac{(1-\alpha) h^{\prime}}{1+\alpha h^{\prime}} \frac{z}{e}
$$

where $z \equiv y / x$ is the ratio of domestic output to exports (imports) and $e \equiv\left(x^{\prime} p\right) / x$ is the elasticity of export supply (import demand). 
reservation price for workers $\bar{p}$ (corner solution). ${ }^{9}$ The corresponding optimal trade policy (either an export tax or an import subsidy) is

$$
t=p^{*}-\bar{p}>0
$$

If instead $p^{*} \geq \bar{p}^{c}$, the optimal domestic price is an interior solution. The optimal trade policy is still given by an export tax or import subsidy, which in this case does not fully compensate consumers. ${ }^{10}$

The optimal trade policy for a small open economy under loss aversion is characterized in the following

Proposition 1 For an international price of food $p^{*} \in[\underline{p}, \bar{p}]$, the optimal food trade policy for a small open economy is free trade. For $p^{*}<\underline{p}$, the optimal policy is an export subsidy for a food exporter and an import tariff for a food importer; a region of full producer compensation (i.e. where $t=p^{*}-\underline{p}$ ) exists for $p^{*} \in\left(\underline{p}^{c}, \underline{p}\right)$. For $p^{*}>\bar{p}$, the optimal policy is an export tax or an import subsidy; a region of full consumer compensation (i.e. where $t=p^{*}-\bar{p}$ ) exists for $p^{*} \in\left(\bar{p}, \bar{p}^{c}\right)$.

Proposition 1 establishes that the optimal food trade policy for a small open economy under loss aversion depends on the international price of food. ${ }^{11}$ This trade policy is depicted in Figure 3. The government does not intervene in the food sector when international prices are at intermediate levels. On the contrary, absent other tools to address loss aversion, a welfare maximizing government may use trade policy in food markets when the international price of food is low (i.e. below the reservation price of land owners/producers, $\underline{p}$ ) or high (above the reservation price of workers/consumers, $\bar{p}$ ). In the first case, the government imposes an export subsidy/import tariff to offset the welfare loss for land owners. In the second case, the policy maker sets an export tax/import subsidy aiming at decreasing the negative effect of high food prices on the utility of workers. In both cases, the rationale behind trade policy is the one of offsetting (completely or in part) the effect that "extreme" conditions in international food markets have on the welfare of domestic constituencies.

The model also has insights on the structure of trade promotion or restriction. When the international price of food moves slightly below the reservation price of producers $(\underline{p})$ or above the reservation

${ }^{9}$ In this case, the FOC is given by

$$
\frac{\partial G}{\partial p}=W^{\prime}+H^{\prime}=\left(p^{*}-p\right) x^{\prime}+(1-\alpha)\left[-y+\left(p^{*}-p\right) x^{\prime}\right] \cdot h^{\prime}=0
$$

The proof of this statement follows the same steps as in footnote 7. Specifically, for an international price of food $p^{*}=\bar{p}+\varepsilon$, with $\varepsilon$ small enough, $W^{\prime}(\bar{p}+\varepsilon)=0$, while $H^{\prime}(\bar{p}+\varepsilon)>0$, which implies $G^{\prime}(\bar{p}+\varepsilon)>0$. In this case, the optimal domestic price of food is a corner solution, which equals the reservation price for workers $\bar{p}$. As $\varepsilon$ increases, the loss aversion effect weakens, while $W^{\prime}(\bar{p})$ becomes more negative. There is a critical level of the world price $p^{*}=\bar{p}^{c}>\bar{p}$, above which the optimal domestic price becomes an interior solution.

${ }^{10}$ In particular, the export tax (import subsidy) can be shown to be

$$
\frac{t}{p^{*}-t}=-\frac{(1-\alpha) h^{\prime}}{1+(1-\alpha) h^{\prime}} \frac{z}{e}
$$

\footnotetext{
${ }^{11}$ Anecdotal evidence confirms that export policy in food sectors is often designed to stabilize domestic prices and avoid losses for specific groups (see Piermartini, 2004). For instance, Papua New Guinea had in place an export tax/subsidy rate for cocoa, coffee, copra, and palm oil equal to one-half the difference between a reference price (calculated as the average of the world price in the previous ten years) and the actual price of the year.
} 
price of consumers $(\bar{p})$, the government intervenes to fully compensate the constituency that is incurring a welfare loss. In other words, there is a range of world prices such that the policy maker sets trade policy to bring the domestic price at the reference level of the group that is experiencing loss aversion. These areas are represented in Figure 3 by the region $\left(\bar{p}, \bar{p}^{c}\right)$ for export taxes/import subsidies and $\left(\underline{p}^{c}, \underline{p}\right)$ for export subsidies/import tariffs. Trade intervention increases as the price of food diverges, since the policy aims at fully compensating the losing constituency (i.e. consumers' protection rises one-to-one with food price increases, producers' protection rises one-to-one with prices decreases). As the world price of food continues to diverge from the reference prices of producers or consumers, the structure of trade policy changes. Intuitively, the marginal cost of trade intervention on welfare net of loss aversion increases, and diminishing sensitivity to losses makes full compensation less attractive. Trade policy is still used to offset increasingly high/low world food prices, but the optimal policy no longer aims at full compensation of the losing constituency.

We have abstracted so far from political economy considerations. As is well know, governments weigh more heavily organized interests that, as a result, receive favorable policies in the form of tariff protection or export subsidies (Grossman and Helpman, 1994). Similarly, within the context of our model, it is immediate to realize that, when the domestic price is "intermediate" $(p \in[\underline{p}, \bar{p}])$, a politically motivated government would set an export subsidy or an import tariff rather than free trade in response to lobbying pressures by land owners. In addition, it can be shown that there is a first region of full producer compensation when the price is low (below $\underline{p}$ ), where the government sets an export subsidy or import tariff given by condition (6). ${ }^{12}$ When the domestic price is high $(p>\bar{p})$, a politically motivated government faces a trade off between political economy considerations and the loss aversion caused by high food prices. However, it is easy to prove that there is a region of full consumer compensation where the loss aversion effect is strong, and the government wants to keep the domestic price constant at $\bar{p}{ }^{13}$ Along this region, the policy maker gradually reduces the subsidy / tariff as the world food price increases.

\subsection{The multiplier effect of trade policy}

The previous section established that, under loss aversion, the government of a small economy may have an incentive to use trade policy in response to excessively high or low food prices in international markets. As discussed, the aim is essentially to insulate the domestic economy from large international price changes. Naturally, a trade measure by a small economy in itself has no effect on world markets. However, if all trading economies face similar incentives to alter their policy simultaneously, an effect on the international price of food can materialize which may induce a further policy response. This

\footnotetext{
${ }^{12}$ The proofs of these statements are omitted as they follow directly from Freund and Ozden (2008).

${ }^{13}$ We only sketch the argument here. Define the political welfare of government as $J=\Omega+H$, where $H$ is defined as in Subsection 2.2, while $\Omega=b \pi+C S+G R$, with $b>1$ representing the political bias. This can be interpreted as the reduced-form of a two stage lobbying game, as in Grossman and Helpman (1994). Denote by $t\left(p^{*}\right)$ the politically optimal subsidy/tariff when the domestic price is intermediate, that is, when $p=p^{*}+t\left(p^{*}\right) \in[\underline{p}, \bar{p}]$. This domestic price is the one for which $G^{\prime}=\Omega^{\prime}=0$. When -as a result of an increase in the world price $p^{*}$ - the domestic price grows slightly above the upper threshold, say when $p=\bar{p}+\epsilon$, we have that $G^{\prime}=\Omega^{\prime}+H^{\prime}>0$, as $\Omega^{\prime}=0$ but $H^{\prime}>0$. For a range of $\epsilon$ small enough, the solution to this maximization problem is a corner solution in which the government utilizes trade policy to keep the domestic price constant at $p=\bar{p}$. This policy consists of gradually reducing the subsidy/tariff $t\left(p^{*}\right)$ as $p^{*}$ increases. When $p^{*}$ grows higher than $\bar{p}$, the optimal policy becomes an export tax / import subsidy.
} 
section provides a formalization of how small economies' simultaneous trade policy interacts with the international price of food.

Consider a trading world made up of a unit mass of small natural food exporters and a unit mass of small natural food importers, each characterized by the economic structure introduced in the previous sections. ${ }^{14}$ The generic exporting country, denoted by $e \in[0,1]$, can set up an export tax / subsidy, while the generic importing country, denoted by $i \in[0,1]$, can set up an import subsidy / tariff. The market equilibrium in the food sector is obtained when global export supply equalizes global import demand:

$$
\int_{0}^{1} x_{e}\left(p^{*}-t(e)\right) d e=\int_{0}^{1} m_{i}\left(p^{*}-t(i)\right) d i .
$$

Equation (8) implicitly defines the world price of food as a function of the import and export policies of the whole set of countries in the world, $p^{*}(t(e), t(i))$. When no country intervenes, the international price corresponds to its free trade level $\left(p^{*}(0,0) \equiv p_{f t}^{*}\right)$. Moreover, for a whatever non-zero measure set of countries $S \subseteq[0,2]$ (whether exporting or importing), it is $d p^{*} / d t_{S} \in(0,1)$, where $t_{S}$ denotes the trade policy of set $S$. While a formal proof of this statement is in appendix, the intuition is straightforward: a simultaneous imposition of export taxes (subsidies) lowers (increases) world supply, while a simultaneous imposition of import subsidies (tariffs) raises (decreases) world demand. Both create an upward (downward) pressure to the world price.

Countries differ in terms of their propensity of intervention. Specifically, developing countries may be more likely to fall below the reference utility of consumers $\bar{U}$ and thus to implement a trade policy of compensating protectionism. As a result, the interval $[\underline{p}, \bar{p}]$, on which the optimal trade policy depends, may well differ across countries. ${ }^{15}$ To capture such heterogeneity, we consider a stylized framework with two groups of identical countries, one with a finite interval $[\underline{p}, \bar{p}]$, the other where fundamentals are such that $\underline{p}=0$ and $\bar{p} \rightarrow \infty$. More precisely, we consider that a measure $E \subseteq[0,1]$ of identical exporters and a measure $I \subseteq[0,1]$ of identical importers exist in which consumers are strictly loss averse $(\bar{U}>0)$ and, thus, for which Proposition 1 holds. In the rest of the world $\left(E^{C}=[0,1] \backslash E\right.$ and $\left.I^{C}=[0,1] \backslash I\right)$, a null value for $\bar{U}$ makes preferences collapse to the standard case. Thus their optimal policy is free trade.

The findings of Proposition 1 applied to sets $E$ and $I$, together with the fact that $d p^{*} / d t_{S} \in(0,1)$ for $S=E$, $I$, highlight an important interaction between trade policy and food prices. Governments respond to high food prices by imposing a trade policy (export taxes or import subsidies) that, if applied symmetrically, increases the world price of food. This may induce further policy intervention. An analogous reasoning applies to low food prices. We refer to this as the multiplier effect of trade policy. Whether this multiplier effect will materialize or not depends on the conditions in global food markets. When the world price of food is at intermediate levels $\left(p^{*} \in[\underline{p}, \bar{p}]\right)$, no government is incentivized to employ an active trade policy, and the multiplier effect is dormant. When, instead, a world price surge (fall) raises governments' protection of consumers (producers) -as in the regions of compensating protection-, a multiplier effect will characterize trade policy.

\footnotetext{
${ }^{14}$ The structure of the trading countries is assumed identical. What makes a fraction of them become food exporters, rather than importers, may for instance be that they are endowed with a greater amount of land, $L$.

${ }^{15}$ Countries may also differ in their mode of intervention. For instance, developed countries generally have a larger set of policy instruments and are, therefore, less likely to use second-best trade policy to fulfill their welfare objectives.
} 
For illustrative purposes, we focus on the price escalation effect of trade policy (export taxes and/or import subsidies). ${ }^{16}$ Assume that an exogenous shock to the international market of food brings the international price under free trade to $p_{f t}^{*}>\bar{p}$. This situation induces each exporting country in $E$ and each importing country in $I$ to impose, respectively, an export tax or import subsidy to shield consumers by maintaining the level of the domestic food price at $\bar{p}$. But as all exporters and importers face the same incentive and act simultaneously, the international price of food is pushed up by the fall in world supply and the surge in world demand. The consequence of this price surge is another round of export taxes and import subsidies that, in turn, lead to higher international prices and even higher export taxes and import subsidies. Note, however, that differently from the initial trade policy, which is the response to a shock in the world food market, subsequent trade measures are the reaction to the policies set by all other countries.

The key insights can be inferred by looking at Figure 4. The figure depicts (i) the optimal trade policy for a small open economy belonging to $E \cup I$ as a function of the international price of food $\left(t\left(p^{*}\right)\right)$ and (ii) the international price of food as a function of the trade policy imposed by the measure $E$ of exporting countries and by the measure $I$ of importing countries $\left(p^{*}(t)\right) .{ }^{17}$ The solution to the system made up of these two functions, $\left(p_{e q}^{*}, t_{e q}\right)$, characterizes the equilibrium in the world market of food and is represented as point $Q$ in Figure $4 .{ }^{18}$

The equilibrium can be described as the result of a process of consecutive tax increases across exporting countries and subsidy increases across importing countries. For the international price $p_{f t}^{*}>\bar{p}$, the corresponding trade policy (export tax and import subsidy) for each individual country is optimally set at level $t_{1}$. However, if all exporters / importers set a policy $t_{1}$, there is an excess demand in the global food market and the international price of food increases to $p_{1}^{*}$. At this price, the initial level of the policy measure is inefficiently low, and each policy maker increases it to $t_{2}$. This multiplicative process stops where the international price curve $\left(p^{*}(t)\right)$ intersects the optimal trade policy $\left(t\left(p^{*}\right)\right)$ : at that point, the uncoordinated behavior of traders has caused the equilibrium international price of food to increase relative to its initial level under free trade. ${ }^{19}$

We formally characterize the relationship between trade policy and food prices in Proposition 2, in which we show that the equilibrium reaction to an exogenous shock to supply or demand of food is greater than the partial response by each trading country taking the policy of the others as given. Any shock to supply or demand is reflected into changes in $p_{f t}^{*}$, which univocally determines the position of function $p^{*}(t)$ in Figure 4.

\footnotetext{
${ }^{16}$ Export subsidies and import tariffs, which instead depress the world price of food, can be discussed in a similar way.

${ }^{17}$ The assumed symmetric structure of the world economy ensures that the policy of compensating protectionism is identical across countries belonging to regions $E, I$, that it, $t(e)=t(i)=t \forall e \in E, i \in I$. Moreover, function $p^{*}(t)$ is depicted as a linear function for illustrative purposes only (see Example 1).

${ }^{18}$ The proof of the uniqueness of this equilibrium is a straightforward geometric implication of the two following general properties of the model: (i) $d p^{*} / d t \in(0,1)$, (ii) $d t / d p^{*}=1$ along the regions of compensating protectionism.

${ }^{19}$ The logic of the result also applies to export subsidies (import tariffs). Low prices induce governments to offer subsidies (tariffs) to compensate producers. However, as all exporters (importers) face similar incentives and enact the export promotion (import restriction) policy at the same time, the effect is to increase the export supply (reduce the import demand) of food in world markets and further depress prices. The multiplier effect of trade policy determines, in this case, an equilibrium of high export subsidies and tariffs and low food prices relative to free trade.
} 
Proposition 2 (i) Along the regions of compensating protectionism identified in Proposition 1, a multiplier effect characterizes trade policy. In particular, it is

$$
\frac{d t}{d p_{f t}^{*}}=\theta \frac{\partial t}{\partial p_{f t}^{*}}
$$

where $\theta$ is given by

$$
\theta=\frac{1}{1-\frac{d p^{*}}{d t}}>1
$$

(ii) There is no multiplier effect when the international price belongs to the interval $[\underline{p}, \bar{p}]$.

Intuitively, the policy response of both exporters and importers magnifies situations of stress in world food markets. Specifically, if world food prices are high, both exporters and importers set trade policy to shield the domestic market from developments in the international market. However, the joint imposition of higher export taxes and higher import subsidies (or, in a political economy context, lower export subsidies and lower import tariffs) contracts world supply and expands world demand, thus resulting in even higher international food prices. ${ }^{20}$

Example 1. Let us provide a simple example of this multiplier effect for a slightly simplified economy in which $E=[0,1]$ and $I=\varnothing$. For simplicity, let us consider linear import demand and export supply. In particular, suppose $x_{e}\left(p^{*}-t\right)=\alpha+\beta\left(p^{*}-t\right) \forall e \in[0,1]$ and $m\left(p^{*}\right)=\gamma-\delta p^{*}$, with $\alpha, \beta, \gamma, \delta \in R_{+}$and where $t$ is a specific export tax (or subsidy if lower than zero). Equilibrium in the world market of food implies

$$
\int_{0}^{1}\left[\alpha+\beta\left(p^{*}-t\right)\right] d e=\gamma-\delta p^{*},
$$

from which we obtain the world price as

$$
p^{*}=p_{f t}^{*}+\eta t
$$

where $\eta \equiv \beta /(\beta+\delta)$ and $p_{f t}^{*} \equiv(\gamma-\alpha) /(\beta+\delta)$ (the untaxed world price). Let us now analyze what happens when $p_{f t}^{*}>\bar{p}$ (the case in which $p_{f t}^{*}<\underline{p}$ is analogous and thus omitted). Along the region of compensating protection, each country $e$ poses $t=p^{*}-\bar{p}$. In a symmetric market equilibrium it holds

$$
\left\{\begin{aligned}
p^{*} & =p_{f t}^{*}+\eta t \\
t & =p^{*}-\bar{p}
\end{aligned}\right.
$$

from which it results

$$
t=\frac{1}{1-\eta}\left(p_{f t}^{*}-\bar{p}\right)>0
$$

Then it is

$$
\frac{d t}{d p_{f t}^{*}}=\theta \frac{\partial t}{\partial p_{f t}^{*}}
$$

\footnotetext{
${ }^{20}$ In the limit case where $E, I=[0,1]$, along the regions of compensating protectionism it is $d p^{*} / d t=1$, and the multiplier is infinite: $\theta \rightarrow \infty$. This result is also proven in the Proof of Proposition 2.
} 
where

$$
\theta \equiv \frac{1}{1-\eta}
$$

is the limit of a geometric series of ratio $\eta$, which in standard economic terminology is usually referred to as the multiplier. This multiplier is finite and strictly higher than 1 as $\eta \equiv \beta /(\beta+\delta) \in(0,1)$.

\subsection{Large economies and the multiplier effect}

Now consider a trading world similar to the one described above, but in which economies are large, in the sense that, in deciding their trade policy, they do not take the world price of food as given but internalize the effect of their measures on the world price. In particular, consider a world economy made up of $N$ large exporting countries and $M$ large importing countries. The market equilibrium in the food sector implies

$$
\sum_{e=1}^{N} x_{e}\left(p^{*}-t_{e}\right)=\sum_{i=1}^{M} m_{i}\left(p^{*}-t_{i}\right),
$$

where $x_{e}(\cdot)$ and $m_{i}(\cdot)$ denote, respectively, the export supply of country $e$ and the import demand of country $i$. Expression (9) implicitly defines the world price as a function of the policies of all trading countries, $p^{*}(\mathbf{t})$, where $\mathbf{t}=\left\{t_{1}, t_{2}, . ., t_{N+M}\right\}$. It can be proven that $p^{*}$ is increasing in any element of vector $\mathbf{t}$. Moreover, if $\mathbf{t}=\mathbf{0}$, then $p^{*}(\mathbf{0})=p_{f t}^{*}$.

Consider a generic country $\omega \in N \cup M$ with the same economic structure as that introduced in Subsection 2.1. Its optimal unilateral policy is the one which maximizes

$$
G_{\omega}\left(t_{\omega}, p^{*}(\mathbf{t})\right)=W_{\omega}\left(t_{\omega}, p^{*}(\mathbf{t})\right)+H_{\omega}\left(t_{\omega}, p^{*}(\mathbf{t})\right)
$$

where, as before, standard social welfare (i.e. net of loss aversion) is the sum of labor income, revenue from the specific factor, consumer surplus and government revenue:

$$
W_{\omega}\left(t_{\omega}, p^{*}(\mathbf{t})\right)=\left(1-\alpha_{\omega}\right)+\pi_{\omega}\left(t_{\omega}, p^{*}(\mathbf{t})\right)+C S_{\omega}\left(t_{\omega}, p^{*}(\mathbf{t})\right)+G R_{\omega}\left(t_{\omega}, p^{*}(\mathbf{t})\right),
$$

while the loss aversion term is defined as

$$
\begin{aligned}
H_{\omega}\left(t_{\omega}, p^{*}(\mathbf{t})\right)= & -\left(1-\alpha_{\omega}\right) I^{l} \cdot h_{\omega}\left[V_{\omega}^{l}(\bar{p})-1-C S_{\omega}\left(t_{\omega}, p^{*}(\mathbf{t})\right)-G R_{\omega}\left(t_{\omega}, p^{*}(\mathbf{t})\right)\right] \\
& -\alpha_{\omega} I^{L} \cdot h_{\omega}\left[V_{\omega}^{L}(\underline{p})-\frac{\pi_{\omega}\left(t_{\omega}, p^{*}(\mathbf{t})\right)}{\alpha_{\omega}}-C S_{\omega}\left(t_{\omega}, p^{*}(\mathbf{t})\right)-G R_{\omega}\left(t_{\omega}, p^{*}(\mathbf{t})\right)\right] .
\end{aligned}
$$

Parameters $\underline{p}$ and $\bar{p}$ are to be interpreted as follows. When the domestic price of country $\omega$ lies inside interval $[\underline{p}, \bar{p}]$, the loss aversion term is null, and the government maximizes function (11). When instead the domestic price in $\omega$ is higher than $\bar{p}$ (lower than $\underline{p}$ ), then $I^{l}=1\left(I^{L}=1\right.$ ), and the government maximizes function (10).

We now characterize the equilibrium trade policy of the world economy. In analogy to the previous case of small trading countries, suppose that a number of identical exporters $E \subseteq[1, N]$ and a number of identical importers $I \subseteq[1, M]$ exist whose consumers are strictly loss averse $(\bar{U}>0)$ and thus for which a non-degenerate interval $[\underline{p}, \bar{p}]$ exists. In the complementary sets $E^{C}$ and $I^{C}$ instead, a null value for $\bar{U}$ once again makes preferences collapse to the standard case. In what follows, we focus on the policy interaction across countries belonging to sets $E$ and $I$, which represents the novel policy 
interaction introduced in this model, and thus assume for simplicity that countries belonging to sets $E^{C}$ and $I^{C}$ are passive. This strategic interaction can be described as a simultaneous game with $E+I$ players, each deciding the trade policy which maximizes its own welfare. As before, different scenarios must be considered depending on whether domestic prices in sets $E$ and $I$ are such that loss aversion plays a role in their problem of welfare maximization.

If loss aversion does not play any role, the best response function of all countries comes from the maximization of (11), and a candidate Nash equilibrium, denoted by $\hat{\mathbf{t}} \equiv\left\{\hat{t}_{E}, \ldots, \hat{t}_{E}, \hat{t}_{I}, \ldots, \hat{t}_{I}\right\}$, is given by the solution to the system made up of the $E+I$ best response functions (one for each country). ${ }^{21}$ Denote by $\hat{p}_{E} \equiv p^{*}(\hat{\mathbf{t}})-\hat{t}_{E}$ the food domestic price in all countries belonging to the exporting set $E$ and by $\hat{p}_{I} \equiv p^{*}(\hat{\mathbf{t}})-\hat{t}_{I}$ the food domestic price in all countries belonging to the importing set $I$, where $\hat{p}_{I}>\hat{p}_{E}$ (given that the optimal policy for countries belonging to $E$ is an export tax, $\hat{t}_{E}>0$, while the one for countries belonging to $I$ is an import tariff, $\hat{t}_{I}<0$ ). If both $\hat{p}_{E}$ and $\hat{p}_{I}$ belong to $[\underline{p}, \bar{p}]$, then the candidate solution $(\hat{\mathbf{t}})$ is indeed a Nash equilibrium of the game.

If instead either $\hat{p}_{E}$ or $\hat{p}_{I}$ (or both) do not belong to $[\underline{p}, \bar{p}]$, loss aversion does play a role, and the best response functions of countries belonging to set $E$ or $I$ (or both) are more generally determined via the maximization of (10). In this case, the equilibrium policy of these countries may be one of compensating protectionism, where the policy maker of each country chooses its trade policy to maintain the domestic price at the reservation level of consumers/producers. In the next proposition we formally prove this statement. In particular, we show that, in analogy to the small country case, two intervals of values for the free trade world price of food exist, for which the equilibrium trade policy of exporters and importers is one of compensating protectionism. Our findings are summarized in the following ${ }^{22}$

Proposition 3 (i) For any $p_{f t}^{*} \in\left(\bar{p}_{f t}, \bar{p}_{f t}^{c}\right)$, the equilibrium trade policy of both exporting and importing countries is one of full consumer compensation, that is, $\mathbf{t}^{c} \equiv\left\{t^{c}, \ldots, t^{c}\right\}$ is such that $p^{*}\left(\mathbf{t}^{c}\right)-t^{c}=\bar{p}$ $\forall e \in E, i \in I$. (ii) For any $p_{f t}^{*} \in\left(\underline{p}_{f t}^{c}, \underline{p}_{f t}\right)$, the equilibrium trade policy of both exporting and importing countries is one of full producer compensation, that is, $\mathbf{t}^{p} \equiv\left\{t^{p}, \ldots, t^{p}\right\}$ is such that $p^{*}\left(\mathbf{t}^{p}\right)-t^{p}=\underline{p}$ $\forall e \in E, i \in I$.

\footnotetext{
${ }^{21}$ As is well-known from the theory and supported by recent evidence (in particular, Broda et al. 2008), countries that have power in international markets have an incentive to set trade policy in order to obtain a terms-of-trade gain (the optimal tariff argument). It can be easily shown that the equilibrium trade policy in the absence of loss aversion is an export tax / import tariff. Specifically, welfare maximizing governments set

$$
\hat{t}_{\omega}=\frac{1}{[n \zeta+(n-1) e]},
$$

for $\omega \in N \cup M$, where $n=N$ if $\omega \in N$ and $n=M$ if $\omega \in M$. Furthermore, $1 / n$ is the share of each country's exports / imports on total exports / imports, and $\zeta$ is the foreign import demand / export supply elasticity and $e$ is the elasticity of export supply / import demand from other countries. The equilibrium tax goes to zero as $n \rightarrow \infty$ (as in Subsection 2.2), and it reaches the standard optimal tax level for $n=1$. Whenever $n \geqslant 2$, the welfare of trading countries would increase if they could coordinate on a higher export tax / import tariff (see, Limao and Saggi, 2013, for a formal discussion of this point in the case of multiple symmetric importers).

${ }^{22}$ The proof of this proposition is slightly more complicated than the one of Proposition 1, the main reason being that, differently from the small country case, here the terms of trade effect breaks the symmetry between importing and exporting countries (as $\hat{t}_{E}>0, \hat{t}_{I}<0$ ). As a result, the regions of compensating protectionism do not exactly coincide between countries in $E$ and those in $I$. In the proof of this proposition, we identify the interval for which the policy of full compensation is optimal for both sets of countries simultaneously.
} 
As in the small country case, along the two regions of compensating protectionism, the loss aversion effect is so strong that all governments set trade policy to maintain their domestic price at the reservation level of land owners/producers or workers/consumers. In particular, large exporters (importers) set a tax (subsidy), $t^{c}>0$, to fully compensate consumers and a subsidy (tariff), $t^{p}<0$, to fully compensate producers. In what follows we show that, along the two regions of compensating protectionism, trade policies of large countries are strategic complements and are thus characterized by a multiplier effect. We can now enunciate the following

Proposition 4 Along the regions of compensating protectionism identified in Proposition 3 (i) trade policies are strategic complements, that is, $d t_{\omega} / d t_{-\omega} \in(0,1), \forall \omega \in E \cup I$; (ii) a multiplier effect characterizes trade policy, in that

$$
\frac{d t_{\omega}}{d p_{f t}^{*}}=\Phi \frac{\partial t_{\omega}}{\partial p_{f t}^{*}} \quad \forall \omega \in E \cup I
$$

where

$$
\Phi=\frac{1}{1-(E+I) \frac{d p^{*}}{d t_{\omega}}}>1
$$

The intuition for these results is straightforward. If country $-\omega$ increases its trade policy $t_{-\omega}$ (export tax or import subsidy), it contributes to increase the world price of food, which in turn leads country $\omega$ to do the same in order to keep its domestic price constant (result (i)). The strategic complementarity of large countries' trade policies is the source of the multiplier effect that several practitioners have observed in food markets during the recent crises. Trade policy complementarity magnifies the effects of an exogenous (common) shock to export supply or import demand of food (as embodied in a change of the untaxed world price of food) (result (ii)). ${ }^{23}$

A graphical representation of the multiplier effect for large trading countries is provided in Figure 5 in the simplest two-country case and linear import demand and export supply (a formal analysis of this case is developed in Example 2 below, where the two "policy active" countries are both exporters). The upward sloping reaction functions capture the strategic complementarity of trade policy in the region of full consumer compensation: ${ }^{24}$ any increase in export restrictions / import promotion by country $\omega$ will lead government $-\omega$ to move its policy in the same direction. If the world market of food is hit by a shock which drives up the (untaxed) international price, the two reaction functions shift outward. To offset consumers' losses, exporters have an incentive to set up higher trade restrictive measures, while importers have an incentive to increase trade promotion measures. This causes a multiplier effect: in the new equilibrium $\left(Q^{\prime}\right.$ in Figure 5), the total policy response (from the initial trade policy $t_{e q}$ to $t_{e q}^{\prime}$ ) is strictly larger than the initial response to the shock (from $t_{e q}$ to $t^{\prime}$ ). ${ }^{25}$

\footnotetext{
${ }^{23}$ Again, in the limit case where $E=N$ and $I=M$, the multiplier is infinite along the regions of compensating protectionism. Details are in the Proof of Proposition 4.

${ }^{24}$ Despite the strategic complementarity, the uniqueness of equilibrium in this policy game is ensured by the fact that the slope of the best-response functions is always strictly lower than 1 .

${ }^{25}$ An important question is whether the multiplier effect implies a need for a trade agreement. In the present model, (i) if all countries are small, there is no need for coordination, as the unilaterally optimal policy is also globally optimal; (ii) if countries are large, coordination allows trading countries to internalize the terms-of-trade effect and thus enhances their welfare, as in the standard literature on trade agreements (Bagwell and Staiger, 2002).
} 
Example 2. We provide an example of a world economy characterized by linear import demand and export supply. Two identical, and policy active, exporting countries exist, which are characterized by export supply $x_{e}\left(p^{*}-t_{e}\right)=a / 2+b / 2 \cdot\left(p^{*}-t_{e}\right) \forall e=1,2$, with $a, b \in R_{+}$and where $t_{e}$ is the country $e$ 's specific export tax (or subsidy if lower than zero). The import demand of a passive importing region is instead given by $m\left(p^{*}\right)=c-d p^{*}$, with $c, d \in R_{+}$(in other words, we are assuming that $E=N=2$ and $\left.I^{c}=M=1\right)$. The world market of food is in equilibrium when

$$
a / 2+b / 2 \cdot\left(p^{*}-t_{1}\right)+a / 2+b / 2 \cdot\left(p^{*}-t_{2}\right)=c-d p^{*},
$$

from which we obtain the world price as

$$
p^{*}=p_{f t}^{*}+v\left(t_{1}+t_{2}\right),
$$

where $v \equiv b /[2(b+d)]$ and $p_{f t}^{*} \equiv(c-a) /(b+d)$ (as it is the world price obtained by posing $t_{1}=$ $\left.t_{2}=0\right)$.

Each country implements the export policy which maximizes its own welfare. Loss aversion does not matter whenever the domestic price is "intermediate" $(p \in[\underline{p}, \bar{p}])$, while it matters when the price is "too high" $(p>\bar{p})$ or "too low" $(p<\underline{p})$.

First suppose that the domestic price is intermediate. In this case, the loss aversion term is null $\left(H_{e}=0\right)$, and each government maximizes expression (11). Under the linear assumptions of this example, solving the FOC gives rise (after some elementary algebra) to the following tax as a function of the international price:

$$
t_{e}=\left(\frac{a}{b}+p^{*}\right) v
$$

The reaction function of country $e$ can then be simply found by substituting for (12) into this last equation, thus obtaining

$$
t_{e}=\frac{v}{1-v^{2}}\left(\frac{a}{b}+p_{f t}^{*}+v t_{-e}\right) .
$$

Posing $t_{e}=t_{-e}=\hat{t}$, the symmetric equilibrium tax policy is

$$
\hat{t}=\frac{v}{1-2 v^{2}}\left(\frac{a}{b}+p_{f t}^{*}\right) .
$$

To characterize the upper region of compensating protection, we need to find the values of $\bar{p}_{f t}$ and $\bar{p}_{f t}^{c}$. The value of $\bar{p}_{f t}$ is, by definition, the one such that the domestic price resulting from policy $\hat{t}$ be equal to $\bar{p}$, that is to say,

$$
p^{*}\left(\hat{t}, \bar{p}_{f t}\right)-\hat{t}=\bar{p}
$$

Exploiting our linear price function in (12) and substituting for the value of $\hat{t}$ found above, we can solve for $\bar{p}_{f t}$ to obtain

$$
\bar{p}_{f t}=\frac{(1-2 v) \frac{a}{b}+\bar{p}\left(1-2 v^{2}\right)}{1-v}
$$

If the world economy fundamentals are such that $p_{f t}^{*}<\bar{p}_{f t}$, then the equilibrium tax is $\hat{t}$.

If $p_{f t}^{*}>\bar{p}_{f t}$ instead, loss aversion matters, and each government maximizes expression (10). The steps necessary to characterize $\bar{p}_{f t}^{c}$ are analogous to those just taken to characterize $\bar{p}_{f t}{ }^{26}$ Since they

\footnotetext{
${ }^{26}$ The maximization of (10) gives rise to an export tax $\breve{t}$, which is strictly higher than $\hat{t}$. This allows us to find the value of the free trade world price such that the domestic price resulting from the equilibrium policy be equal to $\bar{p}$, that is to say, that value of $\bar{p}_{f t}^{c}$ such that $p^{*}\left(\breve{t}, \bar{p}_{f t}^{c}\right)-\breve{t}=\bar{p}$. To find the explicit value for $\bar{p}_{f t}^{c}$ as a function of all the parameters of the model however, we would further need to specify a functional form for both $h(\cdot)$ and for the utility function $u(\cdot)$.
} 
do not add any additional insight, we omit them and study the strategic interaction along this upper region of compensating protection.

We know that, when $p_{f t}^{*} \in\left(\bar{p}_{f t}, \bar{p}_{f t}^{c}\right)$, each country wants to keep its domestic price constant at level $\bar{p}$. Thus it poses $t_{e}=p^{*}-\bar{p}$. The reaction function of country $e$ can then be simply found by substituting for (12) into this last equation, thus obtaining

$$
t_{e}=\frac{p_{f t}^{*}-\bar{p}}{1-v}+\frac{v}{1-v} t_{-e}
$$

Given that $v \in(0,1 / 2)$, it is immediate to prove that export taxes are strategic complements, that is

$$
\frac{d t_{e}}{d t_{-e}}=\frac{v}{1-v}>0
$$

In a symmetric equilibrium it holds

$$
\left\{\begin{aligned}
t_{e} & =\frac{p_{f t}^{*}-\bar{p}}{1-v}+\frac{v}{1-v} t_{-e} \\
t_{e} & =t_{-e}
\end{aligned}\right.
$$

from which we obtain the equilibrium tax as

$$
t_{e q}=\frac{1}{1-2 v}\left(p_{f t}^{*}-\bar{p}\right)>0 .
$$

Then it is

$$
\frac{d t_{e q}}{d p_{f t}^{*}}=\Phi \frac{\partial t_{e q}}{\partial p_{f t}^{*}}
$$

where the multiplier is given by

$$
\Phi \equiv \frac{1}{1-2 v}>1 \text { as } v<\frac{1}{2}
$$

Of course, an analogous reasoning can be carried out to identify the lower region of compensating protectionism, and to show the strategic complementarity of export policies and the existence of a multiplier effect.

\section{Trade policy and the 2008-11 food crisis}

In this section, we empirically test the existence of a multiplier effect in food trade policy. That is, we examine whether the pattern of import and export trade policies that countries implement during periods in which prices move away from their reference point is consistent with our key theoretical prediction. As a preliminary step, we test whether trade policy measures are related with changes in international food prices. We then examine whether countries use trade intervention as a response to trade policy implemented by other governments. As seen in Section 2, this behavior gives rise to a trade policy multiplier effect: an initial shock to world food prices is magnified by trade policy actions. We then tackle the issue of endogeneity of our two key variables (trade policy and prices) to verify the robustness of our empirical findings. In the final part of this section, we evaluate the impact of overall trade policy - import and export - on international prices. Given the two-way relationship between trade policy and world prices, we do this by estimating a system of simultaneous equations.

The focus of our analysis is the time period 2008-2011, which is characterized by high food and other commodity prices. During this period, food prices were more than 80 per cent higher than 
average prices during the period 1990-2006. This surge in prices has been particularly strong in some sectors, namely products such as cereals, dairy products, oils and sugar, where the increase in average prices was higher than 100 per cent. Also price volatility has been significantly high during the last three years compared with 1990-2006 (see Table 1). With respect to trade policy instruments, we center our investigation on the universe of export restrictions and import promotion. This is because, consistently with the theory, during periods of high international food prices countries tend to use these measures to insulate the domestic market. ${ }^{27}$

As discussed in Sections 2.2 and 2.4, governments may set trade policy for political economy and for terms-of-trade reasons. In this context, export restrictions and import promotion may well take the form of a reduction in export subsidies and import tariffs and quotas, rather than an increase in export restrictions and import subsidies. Unfortunately, our data -presented below- do not contain information on subsidies (either export or import). For this reason, in the empirical analysis we are limited to the subset of trade policies encompassing increases in export restrictions (e.g. export prohibitions, taxes, quotas) and reductions in import protection (tariffs and quotas). Despite this data limitation, we still find strong support for the predictions of the theory, as we further elaborate in the rest of the section.

\subsection{Data}

Data on export and import policy implementation come from two different sources: the WTO Trade Monitoring Reports (TMR) and the Global Trade Alert (GTA) databases. The main objective of the WTO monitoring reports is to increase the transparency and understanding of the trade policies and practices of member countries affecting the multilateral trading system. Specifically, the monitoring reports of October 2009, November 2010, March 2011 and November 2011 provide information on the type and the status (date of implementation and date of removal) of trade-related measures that have been implemented by governments after the 2008 global financial crisis. These measures have been notified by WTO members and observer governments to the secretariat of the WTO. Our second source, the Global Trade Alert, is an independent monitoring exercise of policies that affect global trade. The GTA database not only includes information on discriminatory measures provided by governments, but it also contains information collected from other sources, such as the media and trade analysts. An evaluation group composed by expert analysts is responsible for assessing this information and deciding whether to publish it on the website. ${ }^{28}$

A total of 281 relevant trade policy instruments have been recorded in food products during the time period 2008-2011 (see column 3 of Table 2). ${ }^{29}$ Specifically, during this period, 9 countries, on average, have imposed an export restriction and/or have reduced their import protection in a certain product. The number of countries using trade policy varies across products, ranging from less than 5 countries in products such as ground nut and coffee or cacao beans to more than 30 countries in

\footnotetext{
${ }^{27} \mathrm{~A}$ similar exercise could, in principle, be done with export promotion and import restriction for periods where international food prices were historically low and presented a downward trend, such as in the second half of the 1980s.

${ }^{28}$ Data on the state of trade measures are available at http://www.globaltradealert.org/site-statistics

${ }^{29}$ Unfortunately, only in very few instances countries report the size of the measures implemented. With the available information, we are therefore only able to perform a qualitative analysis of the likelihood of the utilization of such measures, rather than a quantification of the determinants of their magnitude.
} 
staple products such as wheat and meslin (42) maize (36) or barely (33). ${ }^{30}$ Table 2 shows the number of periods (months) times the number of countries implementing a trade policy measure in a certain product during 2008-2011. During this time interval, trade measures have covered a total of 5219 periods times products. The previous numbers give an indication of the frequency of trade measures in certain food commodities; to capture their relevance in terms or trade, the share of either imports or exports that are covered by trade measures is presented in column 4 of Table 2. These shares significantly vary across products. For instance, for commodities such as wheat, meslin and cocoa, more than two thirds of trade was covered by trade measures during the time interval 2008-2011. For palm oil, barely and sugar, trade measures covered 50 percent of trade. Finally, around one third of trade is covered by trade measures in commodities such as rice, maize and sunflower seed.

In the instrumental variables approach presented below we use data on rainfall from the Global Precipitation Climatology Project (GPCP) dataset as a source of exogenous weather variation to instrument international prices. ${ }^{31}$ We also use data on elections from the Elections Guide dataset to instrument trade policy utilization. ${ }^{32}$ A more complete description of these data will be provided in Section 3.2.3. The rest of the data are from standard sources. International nominal prices come from the FAO and IMF databases. Data on production shares are also taken from FAO. GDP per capita comes from the World Development Indicators. Monthly data on trade (exports and imports) come from UN Comtrade and from the Global Trade Atlas database. Table 3 shows the summary statistics of all the variables.

\subsection{Testing the multiplier effect of trade policy}

To analyze the impact of international prices and overall trade policy on the probability of imposing a trade policy measure, we regress the following specification using monthly data for a set of 77 countries and 33 commodity products:

$$
\begin{aligned}
\operatorname{Prob}\left(\operatorname{TPU}_{i, k, t}=1\right)= & \beta_{o}+\beta_{1} \Delta \text { price }_{k, t-1}^{*}+\beta_{2} G T P U_{-i, k, t-1}+\beta_{3} \text { Prod_share }_{i, k}+ \\
& +\beta_{4} \log \operatorname{Trade}_{i, k, t-1}+\beta_{5} \log \text { PDPercap }_{i}+\lambda_{t}+\delta_{i}+\gamma_{k}+\varepsilon_{i k t} .
\end{aligned}
$$

$T P U_{i, k, t}$ represents a dichotomous variable that takes the value of one whenever country $i$ implements at least one trade measure (either has a higher export restriction or a lower import tariff or quota) in product $k$ at time $t$ and zero otherwise. ${ }^{33} \Delta$ price $_{k, t-1}^{*}$ is the percentage difference of the price of product $k$ from its reference price $\left(\frac{\text { price }_{k, t-1}-r e f_{-} \text {price } e_{k, t-1}}{\text { ref_price } e_{k, t-1}}\right)$, where the reference price is calculated as the 3 year moving average price. ${ }^{34}$ From the model, we expect the coefficient $\beta_{1}$ to be

\footnotetext{
${ }^{30}$ This figure is likely to underestimate the effective number of trade policy measures that have been implemented. In addition to the lack of information on subsidies discussed above, the reason is that trade measures recorded in each month often include more than a single policy measure. Our data set, however, does not allow us to precisely discern this information.

${ }^{31}$ The data are publicly available on the web at http://precip.gsfc.nasa.gov/

${ }^{32}$ ElectionGuide database is provided by the International Foundation for Electoral Systems (IFES) and is available online at http://www.electionguide.org/

${ }^{33}$ In other words, assuming that a certain country implements a policy measure at time $t$ up to time $t+5$, the variable will be equal to 0 before time $t$, equal to 1 between $t$ and $t+5$, and will become 0 again for $t>t+5$.

${ }^{34}$ Reference prices have also been calculated using five and one year moving averages and the historical averages between 1990 and 2000 and 1990 and 2006. The results are in line with the ones presented in this section.
} 
positive: the higher the price changes from its reference point, the more likely is for any given country to implement or maintain a trade measure in order to shield its domestic market. Global trade policy utilization $\left(G T P U_{-i, k, t-1}\right)$ is the main variable of interest, representing the share of trade that is covered by increases in export restrictions and reductions in import protection in a given product. This is calculated as the weighted sum, in terms of export and import shares of countries different form $i$ implementing an export restriction or an import tariff reduction respectively at time $t-1$ in product $k,\left(\sum_{j \neq i}\left(\frac{e x p_{j, k, t-1}}{\text { Wld Trade }_{k, t-1}}\right.\right.$ exp_res $\left.\left._{j, k, t-1}+\frac{i m p_{j, k, t-1}}{\text { Wld Trade }_{k, t-1}} i m p \_r e d_{j, k, t-1}\right)\right) .{ }^{35}$ According to the theory developed in Section 2, we expect that the higher the level of global trade policy utilization on a certain food product, the higher the probability that country $i$ will also implement a trade measure on that product.

A set of control variables that could potentially have an impact on trade policy utilization is also included in the specification. $\log$ Trade $_{i, k, t-1}$ represents the $\log$ of total trade (exports + imports) of product $k$ in country $i$ at time (month) t. $\log$ GDPpercap $i$ is the per capita GDP of country $i$, calculated between 2000 and 2005, and captures the average level of development of the country. We expect that lower income countries have more limited instruments to react against food crises and therefore resort more easily to trade measures. Prod_share ${ }_{i, k}$ captures the importance of a certain product in the agricultural production of a country. This variable is calculated for 2005 to avoid being influenced by the periods of high prices.

In the regression we also include a set of 4-digit product time (month) and country fixed effects in order to account for unobserved product, time and country specific characteristics. ${ }^{36}$ In addition we include year fixed effects in order to capture the existence of time trends in the regression. Finally we cluster standard errors at product-time level to take into account the fact that the observations in the variables of our main interest (international prices and policies) are not independent or vary very little across products in a certain period.

\subsubsection{Baseline regression results}

The outcomes from regression (13) are reported in Table 4. Columns (1)-(3) present the impact of international prices on trade policy utilization. The first column highlights the results using a logit model, while columns (2) and (3) present the regression results using a linear probability (LP) model. We find that positive deviations from the reference price have a positive and significant impact on trade policy utilization (either having a higher export restriction or lower import protection). Specifically, a one per cent increase from its reference price in $t-1$ increases the probability of implementing a trade policy in $t$ by 0.01 and 0.07 per cent respectively in the logit and linear probability models. Therefore a 20 percent percentage point increase in prices from their reference values, which is almost a one standard deviation in prices, leads to an increase of 0.2 (logit) and 1.4 (LP) percentage points on the likelihood of using trade policy.

\footnotetext{
${ }^{35}$ To avoid that the size of an exporter/importer of a certain product in the international markets is polluted by trade policy measures adopted by countries during periods of crisis, average export and import shares are calculated using data from 2000-2005. In addition, for countries implementing both import and export policy measures in a certain product and period, we use the maximum share between imports and exports as weights.

${ }^{36}$ In the logit model country fixed effects are excluded from the regression. This is done to avoid that the control group of countries that have never implemented a trade measure over the time period considered is excluded from the regression due to perfect identification.
} 
In columns (4)-(6) production shares are included in the regression. Note that the number of observations decreases by around half, due to data availability on agricultural production. However, the introduction of this variable is important to control for omitted variables bias since the error term might otherwise include the effect of country-sector specific variables that affect both trade policy utilization and the overall level of trade policy measures. From the table we see that the results for prices do not change: higher differences from the reference price increase the likelihood of implementing trade policy. In addition, trade policy utilization is more likely in goods with higher production shares. This is because in the food sector, large producers of a certain product tend to be also large consumers of that good.

In columns (7)-(9), we look at the impact of global export and import policies on the probability of imposing a trade measure in country $i$. A positive and significant coefficient of the variable capturing the global trade policy utilization confirms that governments impose trade measures in reaction to the policy imposed by other traders. Specifically, in the logit model, a 1 per cent increase in the share of trade covered by trade measures on a product raises the probability of imposing a trade measure on that product of 0.05 per cent on average. In the LP model, this coefficient is equivalent to 0.6 per cent on average. In other words, a one standard deviation increase in global trade policy utilization, will lead to a 0.75 to 9 per cent increase, depending on the model, in the probability of implementing a trade policy in country $i$. Interestingly, once global trade measures are introduced in the regression, the coefficient on prices becomes smaller and, in the logit specification, loses significance. This is compatible with the prediction of the theoretical model that trade policy utilization is in part driven by other countries' trade measures.

The coefficients of the control variables all have the expected signs. $\beta_{4}$ is positive and significant, implying that countries with higher levels of trade of a product are more inclined to use trade policy in order to protect consumers from high food prices. This finding might be less intuitive for large traders, where the impact of higher levels of trade on the likelihood of policy utilization has opposite signs for exporters and importers due to the existence of terms of trade effects (see Section 2.4). We come back to this point below. Also $\beta_{5}$ is negative and significant, suggesting that the lower the level of per capita income of a country and the higher the probability of using trade policy. During periods of high food prices, there are two reasons why low-income countries may be more inclined to impose higher export restrictions or lower tariffs. First, people in developing economies spend a higher share of their income on food. Second, these countries generally have a more limited number of domestic policy instruments available to protect consumers from an increase in domestic food prices. This variable however, loses significance once production shares are included in the regression.

Table 5 presents the regression results for the subsample of staple products such as corn, wheat or sugar that - compared to processed products such as beef, oils and fats or coffee - constitute a dominant portion of a standard diet of a large part of the world population. They might also display higher price volatility due to unstable weather conditions and therefore, the presumption is that these products should be more prone to trade policy intervention. As we will use data on rainfall to instrument international food prices in Section 3.3, the focus on staple foods is also more appropriate as a comparison with the results of the instrumental variables approach. The impact of international price deviations from their reference point on the probability of trade policy utilization for staple foods more than doubles: after controlling for global trade policy measures, a 1 percent increase in 
international price deviations leads to an almost 6 percent increase on the probability of trade policy utilization. The coefficient on the impact of global trade policy is very similar to the one of the overall sample of food products and equivalent to 0.56.

\subsubsection{Are large traders different?}

Next we investigate whether larger traders (either exporters or importers) are more likely to use trade policy when international prices are increasing or as a reaction to other countries' trade policies. In order to do this, we introduce an interaction term between large traders and global trade policy in the baseline regression. The term representing a large trader is captured by a dichotomous variable equal to one if the share of country $i$ 's exports (imports) over world exports (imports) of a certain product $k$ is above the 75 th percentile.

The results are presented in Table 6 . The outcomes from the first 4 columns are for large importers for respectively the whole sample of food products (columns (1) and (2)) and the subsample of staple food products (columns (3) and (4)). For large exporters the results are presented in the last 4 columns, once again for the full sample (columns (5) and (6)) and for staple foods (columns (7) and $(8)) \cdot{ }^{37}$

Being a large importer (exporter) has a negative (positive) impact on the probability of imposing a trade measure. While exporters would tend to impose export restrictions in order to take advantage of the terms of trade effect, importers would tend to avoid tariff reductions for the same reason.

The interaction between international price changes and large importers or exporters is positive and significant for the whole sample of products, implying that large traders react more to increases in food price changes. However, for the subsample of staple foods this interaction is not significant. A possible interpretation of this result is that for staple products all countries react in the same way to price deviations, independently of whether they are large or small. This is consistent with the wiev that avoiding consumer losses is an important objective for countries' trade policy in staple foods given the relevance of such products in the diet of their population. In this respect, as highlighted by the theory, one should expect no difference between large and small economies.

Finally, the interaction between being a large trader (either importer or exporter) and the variable capturing global trade policy utilization is positive in both cases consistently with the existence of a multiplier effect. This also suggests that the effect of global trade policy utilization on the probability of imposing a trade measure is magnified for large players in international food markets.

\subsubsection{Endogeneity}

A possible concern with the previous estimations is that international prices and global trade policy utilization are likely to be endogenous due to the presence of simultaneity bias (as we found in the theoretical model). To deal with this problem we use two different strategies.

First, we perform our regressions increasing the number of lags in the independent variables of interest. Specifically, estimations are performed calculating international price changes from their reference point and global trade policy utilization in $t-2$ and $t-3$ respectively for both the broader

\footnotetext{
${ }^{37}$ To save space, in the table we present the estimation results excluding country fixed effects. Results, available under request, still hold.
} 
sample of all food products and the subset of staple food products. The results, presented in Appendix Table 1, show that, with the exception of the coefficient on prices changes in $t-3$ for the whole sample of products (which are not significant), the magnitudes of the impact of international price deviations and of global trade policy utilization on the probability of imposing a trade measure are very similar to the ones in our baseline regressions (Table 4). ${ }^{38}$ We also interact the dichotomous variables capturing large traders with the lagged global trade measures. The results in Appendix Table 2 are, once more, very similar to the findings in Table 6.

As a second strategy to address the endogeneity bias, we follow an instrumental variables (IV) approach to estimate specification (13). For the international price variable we generate two different instruments based on climatic conditions, more specifically rainfall, which have a direct impact on the total production of food products and, therefore, affect their prices in international markets through the supply channel. The first instrument $\log$ Rain $_{k t}$ measures the total level of rainfall taking place in the top 3 producer countries of a certain product $k$ at time (i.e. month) $t .{ }^{39}$ The second instrument, Rainvar $_{k t}$, captures the total variability of rainfalls in the top 3 producer countries of a certain product $k$ at time $t^{40}$

In order to have a more meaningful instrument for international prices, as identification strategy we focus only on the subsample of staple foods, for which weather conditions are more closely related with prices. For processed food products such as meat, the impact of rainfall on prices is indirect and derives, for instance, from changes in input prices such as animal fodder, e.g. corn. Therefore, the impact of rainfall on top meat producers such as Argentina does not necessarily reflect price movements due only to its own climate conditions; prices may move due to changes in the price of animal fodder, which is mainly produced in other locations such as the United States and is, therefore, dependent on weather conditions in other regions.

The results from the first stage regression of the IV specification, presented in columns (1) - (6) of Appendix Table 3, suggest that rainfall is a good predictor for the international prices variable. High levels of rainfall are negatively correlated with staple food production and, therefore, lead to higher international prices. In addition, the higher the number of top producers experiencing levels of rainfall that highly deviate from their historical mean, the higher the negative impact on total production.

For the global trade policy utilization in a product $k$ we use two instruments. The first instrument, Elections $_{k t}$, is a variable that indicates whether there will be elections taking place in the next six months in the top 3 exporter or importer countries. As discussed at the end of Section 2.2, groups representing producers' interests lobby against trade measures that negatively affect their welfare. In the proximity of elections, governments may be more willing to cede to requests from these special interests and, hence, are less likely to impose a restrictive export measure or to lower the level of existing import protection. ${ }^{41}$ As a second instrument, we use the total number of measures that have

\footnotetext{
${ }^{38}$ The table presents the estimation results for the linear probability model. Results for the logit model are qualitatively similar.

${ }^{39}$ Alternative instruments have been created considering the top 5 and the top 10 producers of a product. The main results still hold and do not change significantly.

${ }^{40}$ This instrument is computed as the total count of top producers for which the amount of rain in a certain month has been either above the 75 th percentile or below the 25 th percentile compared to its historical mean.

${ }^{41}$ The relationship between elections and trade policy could be different from the one described by standard lobbying models for autocratic countries. However, based on the democracy scores from the Polity dataset, none of the large importers and exporters experiencing elections between 2008 and 2011 is an autocratic regime (with a democracy score
} 
been applied in the two-digit industry to which the product belongs, excluding the product itself $\left(T M_{-k t}=\sum_{i} \sum_{j \neq k}\right.$ Trade_Measure $\left._{i j t}\right)$. During periods of increasing food prices, countries might react to the fact that international markets are getting more responsive by imposing trade measures themselves. This may be the result of a sort of "simulation effect" or may occur because countries expect increasing prices in product $k$ deriving from shifts in international demand caused by measures imposed in other products.

The first stage results for the IV specification confirm a negative correlation between the global level of trade policy in a product and the variable capturing elections in large producing countries (the first instrument) and a positive correlation with the number of trade measures in the corresponding industry (the second instrument). The F-statistics of the regressions indicate that none of the instruments are weak (see Appendix Table 3).

Second stage regression results are presented in Table 7. The first three columns are introduced for comparison and report the baseline coefficients of the two main variables of interest (international price deviations and global trade policy utilization) for all countries, large importers and large exporters respectively. ${ }^{42}$ The rest of the columns display second stage results. The coefficients on international prices are positive and significant: a one percent increase in the deviation from the reference price increases the likelihood of imposing a trade measure by 0.47 on average. For large importers the coefficients are slightly smaller (0.40), while for large exporters they are higher (0.6). Note that the magnitude of the impact of price deviations is somehow bigger compared to the ones of the baseline regressions (see columns (1)-(3)). The reason is that international food prices might be subject to measurement error due to the existence of price speculation activities that are not necessarily linked with actual food supply availability. Moreover, measurement error can also derive from the fact that international prices of commodities, such as rice, are composites of products of different quality and different production processes (e.g. basmati rice, kasmati rice, thai rice etc). If our claim is right, then the price coefficients in the IV regressions suggest that the attenuation bias deriving from measurement error in the baseline regression is higher than the endogeneity bias. In this case, the coefficients from the IV specification reflect a more robust impact of price deviations on trade policy utilization. ${ }^{43}$

Global trade policy utilization is still found to have a positive and significant impact on the probability of imposing a trade measure. For this variable, the magnitudes of the coefficients in the IV regressions are in line with the ones of the baseline regressions reported in columns (1) to (3). Specifically, a 1 percent increase in the share of world trade covered by increases in export restrictions and reductions in import protection increases the likelihood of using trade policy by almost 6 percent, on average. This coefficient is very similar for large exporters (0.6) and slightly smaller for large importers (0.5).

\footnotetext{
$<6$ of the Polity IV index).

${ }^{42}$ Note that here the number of observations for the baseline regression are smaller than in Table 4 due to the lack of elections data for all the countries in the original sample.

${ }^{43}$ Our discussion is in line with Miguel et al. (2004) that highlight the problem of mismeasured explanatory variables, such as per capita GDP, in an instrumental variables approach.
} 


\subsection{The impact of trade policy on food prices}

The empirical analysis so far has shown that countries set trade policy in response to developments in international food markets, as captured by deviations in the world price of food from their reference price and that they react to the trade policy utilization of their trade partners. As we discussed, this evidence is compatible with the existence of a multiplier effect in food trade policy. A compelling, but rather difficult, issue is to assess the overall impact that trade policy measures had on international food prices during the 2008-11 food crisis. The difficulty lies in the fact that trade policy utilization is endogenous. As shown in the theoretical model in Section 2, trade measures may be induced by increases in international food prices, which in turn are affected by trade policy. To deal with this endogeneity, we use a two-stage least squares (2SLS) approach in order to estimate the following system of simultaneous equations consistent with our theoretical model:

$\left\{\begin{array}{l}\Delta \text { price }_{k, t}^{*}=\alpha_{0}+\alpha_{1} \text { GTPU }_{k, t}+\alpha_{2} \log \text { Rain }_{k, t}+\alpha_{3} \text { Rainvar }_{k, t}+\alpha_{4} \Delta \text { Energy }_{t}+\gamma_{k}+\lambda_{t}+\varepsilon_{k t} \\ \operatorname{GTPU}_{k, t}=\beta_{0}+\beta_{1} \Delta \text { price }_{k, t-1}^{*}+\beta_{2} \text { Elections }_{k, t}+\beta_{3} \text { TM }_{-k, t}+\lambda_{t}+\gamma_{k}+u_{k t} .\end{array}\right.$

The first equation of the system is the one of our interest and represents the percentage change of world prices of product $k$ at time $t$ from its reference price as a function of global trade policy utilization. ${ }^{44}$ We expect that the overall increases in export restrictions and decreases in import protection on product $k$ will have a positive impact on its international price. In the specification, we introduce a set of time-varying control variables that could potentially affect the international price. These variables include the total level and the variability of rainfall in the top producer countries (as defined in the previous subsection) and the monthly changes in energy prices. Finally, $\gamma_{k}$ and $\lambda_{t}$ are a set of product and time fixed effects. The second equation of the system represents global trade policy utilization on product $k$. This variable depends on the level of international prices, because increases in the positive price deviations of product $k$ are expected to induce governments to use trade policy to address consumers' losses. As additional explanatory variable in the regression, we include the instruments measuring the proximity of elections in top importing and exporting countries and the number of trade measures at the two-digit industry level (excluding product $k$ ), and time and product fixed effects.

The second stage results for the subsample of staple food are presented in Table 8 for different measures of price deviations (i.e. using as reference price the 3 and 5 years moving average and the historical average for the period 1980-2006 and 2000-2006). They provide further evidence of the existence of a multiplier effect of trade policy in the food sector. Global trade policy utilization in a certain product $k$ has a positive and significant impact on the international prices of that product. Specifically, a 1 per cent increase in the share of world trade covered by export and import measures raises international price changes from their reference point between 0.4 and 2.1 percent, depending on the reference price taken into consideration. This implies that a one standard deviation increase in global trade policy utilization led prices in staple food products to increase by a range of 8 and 42 per cent in 2008-2011. Interestingly, the magnitude of this effect is comparable to other studies on

\footnotetext{
${ }^{44}$ Note that here, differently from previous subsections, the global trade policy utilization variable includes all countries in the sample. Formally, the variable is defined as follows: GTPU $U_{k, t}=$

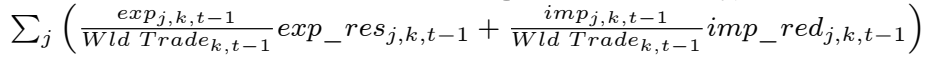


the impact of trade policy on world food prices of staple foods, most notably Anderson and Martin (2011), notwithstanding the differences in methodology discussed in the introduction.

\section{Conclusions}

In his essay "Of the Balance of Trade", David Hume wrote:

"It is very usual, in nations ignorant of the nature of commerce, to prohibit the exportation of commodities, and to preserve among themselves whatever they think valuable and useful. They do not consider, that, in this prohibition, they act directly contrary to their intention ... To this day, in France, the exportation of corn is almost always prohibited; in order, as they say, to prevent famines; though it is evident, that nothing contributes more to the frequent famines, which so much distress that fertile country." (Hume, 1742).

As this quote reminds us, economists have for long time believed that a link exists between trade policy and food crises. This paper fits in this tradition by presenting a model of food trade policy when agents are averse to losses. The theory predicts that exporting (importing) governments offer export subsidies (import tariffs) when food prices are low and set export taxes (import subsidies) when prices are high. Moreover, the theory formalizes a significant channel through which these policy actions can destabilize global food markets. This results from a multiplier effect, similar to the concept familiar in macroeconomic theory, where world food price changes feed into increasingly trade policy activism.

We test empirically the theory focusing on 2008-11, a period of high and volatile food prices and trade policy activism. In particular, we investigate the presence of a multiplier effect in food trade policy from two angles. First, we study whether governments set trade policy in response to measures imposed by other countries to insulate their domestic food markets. Second, we analyze the impact of trade policy on international food prices. In the empirical analysis we employ a novel dataset that contains detailed information on actual trade policy choices taken by governments. Our results confirm that trade measures are set in response to increased trade policy utilization by other

governments, particularly for important products such as staple foods. Moreover, the overall impact of these measures has been to significantly increase staple food prices in 2008-11. 


\section{References}

[1] Aksoy, M.A. and B.M. Hoekman (2011). "Food Prices and Poverty: Introduction and Overview". In Aksoy and Hoekman eds. Food Prices and Poverty. World Bank.

[2] Anderson, K. and W. Martin (2011). "Export Restrictions and Price Insulation during Commodity Price Booms". World Bank Policy Research Working Paper No. 5645.

[3] Bagwell, K. and R.W. Staiger (2001). "Strategic Trade, Competitive Industries and Agricultural Trade Disputes". Economics and Politics, 13: 113-28.

[4] Bagwell, K. and R.W. Staiger (2002). The Economics of the World Trading System. MIT Press, Cambridge.

[5] Bouet, A. and G. Laborde (2010). "Food Crisis and Export Taxation: The Cost of NonCooperative Trade Policies". Review of World Economics, 148:1, 209-233.

[6] Broda, C., D. Weinstein and N. Limao (2008). "Optimal Tariffs and Market Power: The Evidence." American Economic Review, 98(5), pp. 2032-65

[7] Camerer, C. (1995). "Individual decision making", in Handbook of Experimental Economics, ed. by A. R. J. Kagel, Princeton University Press, vol. 2.

[8] Chauffour, J.P. (2008). "Global Food Price Crisis: Trade Policy Origins and Options". PREM Trade Note No. 119. World Bank.

[9] Deaton, A. and G. Laroque (1992). "On the Behaviour of Commodity Prices". Review of Economic Studies, 59:1, 1-23.

[10] Freund, C. and C. Ozden (2008). "Trade Policy and Loss Aversion". American Economic Review, 98:4, 1675-91.

[11] Gouel C. and S. Jean (2013). "Optimal food price stabilization in a small open developing country". Forthcoming, World Bank Economic Review.

[12] Grossman, G.M. and E. Helpman (1994). "Protection for Sale". American Economic Review, $84: 4,833-850$.

[13] Headey, D. (2011). "Rethinking the Global Food Crisis: The Role of Trade Shocks". Food Policy, $36,136-46$.

[14] Hochman, G., D. Rajagopal, G. Timilsina, and D. Zilberman (2011). "Quantifying the causes of the global food commodity price crisis", World Bank Policy Research Working Paper No. 5744.

[15] Hume, D. (1742). "Of the Balance of Trade". Reprinted in Essays: Moral, Political and Literary. Liberty Fund, Indianapolis.

[16] Ivanic, M., W. Martin and H. Zaman (2011). "Welfare and Price Impacts of Price Insulating Policies". World Bank Policy Research Working Paper No. 5633. 
[17] Kahneman, D. and A. Tversky (1979). "Prospect theory: an analysis of choice under risk", Econometrica, 47, 263-291.

[18] Koszegi, B. and M. Rabin (2006). "A Model of Reference-Dependent Preferences", Quarterly Journal of Economics, 121, 1133-1165.

[19] Limao, N. and K. Saggi (2013). "Size Inequality, Coordination Externalities and International Trade Agreements". European Economic Review, 63, 10-27.

[20] Limao, N. and P. Tovar (2009). "Policy Choice: Theory and Evidence from Commitment via International Trade Agreements". Journal of International Economics, 85:2, 186-205.

[21] Miguel, E., S. Satyanath and E. Sergenti (2004). "Economic Shocks and Civil Conflict: An Instrumental Variables Approach". Journal of Political Economy, 112:4, 725-753.

[22] Piermartini, R. (2004). "The Role of Export Taxes in the Field of Primary Commodities". WTO Discussion Paper. Geneva, World Trade Organization.

[23] Samuelson, W. and R. Zeckhauser (1988). "Status quo bias in decision making", Journal of Risk and Uncertainty, 1, 7-59.

[24] Tovar, P. (2009). "The Effects of Loss Aversion on Trade Policy: Theory and Evidence". Journal of International Economics, 78, 154-67.

[25] Tversky, A. and D. Kahneman (1981). "The framing of decisions and the psychology of choice," Science, 211, 453-458.

[26] Tversky, A. and D. Kahneman (1991). "Loss Aversion in Riskless Choice: A Reference-Dependent Model", Quarterly Journal of Economics, 106, 1039-1061. 


\section{A Proofs}

Proof of Proposition 1. The proof of Proposition 1 follows, mutatis mutandis, from Freund and Ozden (2008) and is thus omitted. See footnotes 8-12.

Proof of Proposition 2. (i) We prove the existence of the multiplier effect of export taxes / import subsidies when $p^{*} \in\left(\bar{p}, \bar{p}^{c}\right) .{ }^{45}$ In this case, the policy rules of countries belonging to $E$ and $I$ are identical and captured by expression $t=p^{*}-\bar{p}$. However, while each country takes $p^{*}$ as given (being too small to affect it), its value is affected by the trade policy implemented by the whole set of trading countries. World price $p^{*}$ is implicitly defined by (8), while the untaxed world price $p_{f t}^{*}$ is implicitly defined by the laissez faire equilibrium in the world market, $m\left(p_{f t}^{*}\right)=x\left(p_{f t}^{*}\right)$. We can then define the world price as an increasing function of the trade policy of sets of countries $E, I$ and of the free trade world price, $p^{*}\left(t, p_{f t}^{*}\right)$, where $p_{f t}^{*}$ parameterizes the world price function and captures any shock that affects functions $m(\cdot)$ or $x(\cdot)$ other than changes in trade policies.

The equilibrium trade policy (export tax or import subsidy) in $E$ and $I$ is implicitly defined by

$$
t=p^{*}\left(t, p_{f t}^{*}\right)-\bar{p}
$$

The total derivative of $t$ with respect to $p_{f t}^{*}$ can be written as

$$
\frac{d t}{d p_{f t}^{*}}=\frac{\partial p^{*}}{\partial p_{f t}^{*}}+\frac{d p^{*}}{d t} \frac{d t}{d p_{f t}^{*}}
$$

from which, given that $\partial t / \partial p_{f t}^{*}=\partial p^{*} / \partial p_{f t}^{*}$, we easily obtain

$$
\frac{d t}{d p_{f t}^{*}}=\theta \frac{\partial t}{\partial p_{f t}^{*}}
$$

where

$$
\theta=\frac{1}{1-\frac{d p^{*}}{d t}} .
$$

To prove that $\theta>1$, we now show that $d p^{*} / d t \in(0,1)$ when $E, I \subset[0,1]$ (and, in particular, that it is exactly equal to 1 when $E, I=[0,1]$ ). The global food export supply and the global food import demand can be, respectively, disaggregated into

$$
\begin{aligned}
x\left(p^{*}, t(e)\right) & \equiv x_{E}\left(p^{*}-t\right)+x_{E^{C}}\left(p^{*}\right), \\
m\left(p^{*}, t(i)\right) & \equiv m_{I}\left(p^{*}-t\right)+m_{I^{C}}\left(p^{*}\right)
\end{aligned}
$$

where $E^{C}=[0,1] \backslash E$ and $I^{C}=[0,1] \backslash I$. Totally deriving the equilibrium condition, $x\left(p^{*}, t(e)\right)=$ $m\left(p^{*}, t(i)\right)$, we can express $d p^{*} / d t$ as

$$
\frac{d p^{*}}{d t}=\frac{\frac{d m_{I}}{d t}-\frac{d x_{E}}{d t}}{\frac{d x_{E}}{d p^{*}}+\frac{d x_{E} C}{d p^{*}}-\frac{d m_{I}}{d p^{*}}-\frac{d m_{I} C}{d p^{*}}} .
$$

The expression above is strictly positive given that, for standard demands and supplies, it holds $d m_{I} / d t, d x_{E} / d p^{*}, d x_{E^{C}} / d p^{*}>0$ and $d x_{E} / d t, d m_{I} / d p^{*}, d m_{I}^{C} / d p^{*}<0$. On the other hand, the fact

\footnotetext{
${ }^{45}$ The proof for the multiplier effect of export subsidies / import tariffs, when $p^{*} \in\left(\underline{p}^{c}, \underline{p}\right)$, is totally analogous and is thus omitted.
} 
that $-d x_{E} / d t=d x_{E} / d p^{*}, d m_{I} / d t=-d m_{I} / d p^{*}$ and that $d x_{E^{C}} / d p^{*}>0, d m_{I}^{C} / d p^{*}<0$ ensures that the numerator of (14) is lower than the denominator, and hence that $d p^{*} / d t<1$. In particular, when $E, I=[0,1]$, it is $d x_{E^{C}} / d p^{*}=d m_{I}^{C} / d p^{*}=0$, implying $d p^{*} / d t=1$ and hence an infinite multiplier, $\theta \rightarrow \infty$.

(ii) For $p^{*} \in[\underline{p}, \bar{p}]$, we have that $t\left(p^{*}\right)=0$ for all countries in the sets $E$, I, implying that $p^{*}\left(0, p_{f t}^{*}\right)=p_{f t}^{*}$.

Proof of Proposition 3. (i) Full consumer compensation policy. World price $p^{*}$ is defined implicitly by (9), while the untaxed world price $p_{f t}^{*}$ is defined implicitly by the laissez faire equilibrium in the world market, $\sum_{i=1}^{n} m_{i}\left(p_{f t}^{*}\right)=\sum_{e=1}^{n} x_{e}\left(p_{f t}^{*}\right)$. As in the small country case, it is useful to define the world price as a function of both trade policy and of the untaxed world price, $p^{*}\left(\mathbf{t}_{E \cup I}, \mathbf{t}_{(E \cup I)^{c}}, p_{f t}^{*}\right)$, where $\mathbf{t}_{E \cup I}$ and $\mathbf{t}_{(E \cup I)^{c}}$ denote the vectors of trade policies in, respectively, $E \cup I$ and $(E \cup I)^{c}$, and $p_{f t}^{*}$ parameterizes the world price function, thus capturing all exogenous forces affecting import demand and export supply other than trade policies. Given that countries in the set $(E \cup I)^{c}$ are passive, their trade policies are simply parameters of the game. To simplify the notation, we then remove them from the world price function and denote the vector of strategic variables of the game, $\mathbf{t}_{E \cup I}$, as the pair $\left(\mathbf{t}_{I}, \mathbf{t}_{E}\right)$ to explicitly distinguish between exporters and importers.

The logic of the proof goes as follows. We first identify the interval of world food prices $p_{f t}$ for which the importers' best response policy to the exporters' policy of compensating protectionism is itself a policy of compensating protectionism. We then identify the same interval of world food prices for exporters, and we finally show that the intersection between these two intervals is the range of values for which a policy of compensating protectionism for both importers and exporters is a Nash equilibrium of the policy game.

Let us start with the characterization of the importers' interval. Define (a) $\widehat{\bar{p}}_{f t}$ as the value of the free trade world price such that, if exporters set up a policy of full consumer compensation $\left(\mathbf{t}_{E}^{c}\right)$ and importers a policy resulting from the maximization of (11) (denote it by $\hat{\mathbf{t}}_{I}$ ), the resulting domestic price is equal to $\bar{p}$ :

$$
\widehat{\bar{p}}_{f t}: p^{*}\left(\hat{\mathbf{t}}_{I}, \mathbf{t}_{E}^{c}, \widehat{\bar{p}}_{f t}\right)-\hat{t}_{I}=\bar{p} ;
$$

(b) $\bar{p}_{f t}^{c}$ as the value of the free trade world price such that, if exporters set up a policy of full consumer compensation $\left(\mathbf{t}_{E}^{c}\right)$ and importers a policy resulting from the maximization of (10) (denote it by $\breve{\mathbf{t}}_{I}$ ), the resulting domestic price is equal to $\bar{p}$ :

$$
\bar{p}_{f t}^{c}: p^{*}\left(\breve{\mathbf{t}}_{I}, \mathbf{t}_{\mathbf{E}}^{\mathbf{c}}, \bar{p}_{f t}^{c}\right)-\breve{t}_{I}=\bar{p},
$$

First it can be shown that $\widehat{\bar{p}}_{f t}<\bar{p}_{f t}^{c}$. This results from exploiting the following three facts in expressions (15) and (16): (1) $\breve{\mathbf{t}}_{I}$ is strictly higher than $\hat{\mathbf{t}}_{I}$ for any value of $\mathbf{t}_{\mathbf{E}}$; (2) the domestic price in country $\omega$ is a decreasing function of $t_{\omega} \forall \omega \in E \cup I$; (3) the equilibrium world price $p^{*}$ is increasing in $p_{f t}^{*} \cdot{ }^{46}$ Facts (1) and (2) imply a lower domestic price associated to policy $\breve{\mathbf{t}}$. Hence, in order for both domestic prices to be exactly equal to $\bar{p}$ as in (15) and (16), fact (3) implies $\widehat{\bar{p}}_{f t}<\bar{p}_{f t}^{c}$.

\footnotetext{
${ }^{46}$ Fact (1) can be proven as follows. Policy $\hat{\mathbf{t}}_{I}$ is the one for which $W_{I}^{\prime}\left(\hat{\mathbf{t}}_{I}, \mathbf{t}_{\mathbf{E}}\right)=0$. Moreover, for any $\mathbf{t}_{I}>\hat{\mathbf{t}}_{I}\left(\mathbf{t}_{I}<\hat{\mathbf{t}}_{I}\right)$, it is $W_{I}^{\prime}\left(\hat{\mathbf{t}}_{I}, \mathbf{t}_{\mathbf{E}}\right)<0\left(W_{I}^{\prime}\left(\hat{\mathbf{t}}_{I}, \mathbf{t}_{\mathbf{E}}\right)>0\right)$. Policy $\breve{\mathbf{t}}_{I}$ is instead the one such that $W_{I}^{\prime}\left(\breve{\mathbf{t}}_{I}, \mathbf{t}_{\mathbf{E}}\right)+H_{I}^{\prime}\left(\breve{\mathbf{t}}_{I}, \mathbf{t}_{\mathbf{E}}\right)=0$. Given that, where it is defined, $H_{I}^{\prime}(\cdot)>0$, it must be $W_{I}^{\prime}\left(\breve{\mathbf{t}}_{I}, \mathbf{t}_{\mathbf{E}}\right)<0$, which only occurs for policy values strictly higher than $\hat{\mathbf{t}}_{I}$. To prove Fact (2), first notice that $d p_{\omega} / d t_{\omega}=d p^{*} / d t_{\omega}-1$. Then, it suffices to prove that $d p^{*} / d t_{\omega}$ is lower than 1 $\forall \omega \in E \cup I$, which is done in the proof of Proposition 4 below. Fact (3) is true by definition of $p^{*}$ and $p_{f t}^{*}$.
} 
Secondly, we can interpret these two thresholds as follows. For any $p_{f t}>\widehat{\bar{p}}_{f t}$, loss aversion matters for importers (given that fact (3) applied to (15) implies a domestic price higher than $\bar{p}$ ). On the other hand, for any $p_{f t}<\bar{p}_{f t}^{c}$, the loss aversion effect is so strong that a corner solution is optimal for importers (given that fact (3) applied to (16) implies a domestic price lower than $\bar{p}$ ). As a result, and by construction, for any $p_{f t} \in\left[\widehat{\bar{p}}_{f t}, \bar{p}_{f t}^{c}\right]$ the best response of importers to exporters' policy of full consumer compensation is a policy of full consumer compensation.

Exactly the same steps can be carried out to define the analogous interval for exporters, that is, define $\bar{p}_{f t}$ as the one such that

$$
p^{*}\left(\mathbf{t}_{I}^{c}, \hat{\mathbf{t}}_{E}, \bar{p}_{f t}\right)-\hat{t}_{E}=\bar{p}
$$

and $\breve{p}_{f t}^{c}$ as the one such that

$$
p^{*}\left(\mathbf{t}_{I}^{c}, \breve{\mathbf{t}}_{E}, \breve{p}_{f t}^{c}\right)-\breve{t}_{E}=\bar{p} .
$$

Facts (1), (2) and (3) applied to this context imply $\bar{p}_{f t}<\overline{\breve{p}}_{f t}^{c}$. By the same argument developed above for importers, for any $p_{f t} \in\left[\bar{p}_{f t}, \overline{\bar{p}}_{f t}^{c}\right]$ the best response of exporters to the importers' policy of full consumer compensation is a policy of full consumer compensation.

We now also show that it holds $\widehat{\bar{p}}_{f t}<\bar{p}_{f t}$ and $\bar{p}_{f t}^{c}<\overline{\bar{p}}_{f t}^{c}$. Consider the first inequality. The terms of trade effect -which biases policy intervention towards an import tariff $\left(\hat{t}_{I}<0\right)$ and an export tax $\left(\hat{t}_{E}>0\right.$, see footnote 23), implies a higher domestic price in importing countries than in exporting countries. Hence, in order for both domestic prices to be exactly equal to $\bar{p}$ in (15) and (17), fact (3) implies $\widehat{\bar{p}}_{f t}<\bar{p}_{f t}$. A totally analogous argument proves that $\bar{p}_{f t}^{c}<\bar{p}_{f t}^{c}$.

As a result, if $\left[\widehat{\bar{p}}_{f t}, \bar{p}_{f t}^{c}\right] \cap\left[\bar{p}_{f t}, \overline{\bar{p}}_{f t}^{c}\right]=\left(\bar{p}_{f t}, \bar{p}_{f t}^{c}\right) \neq \varnothing$ then, along this interval, country $\omega$ 's best response to country $-\omega$ 's policy of full consumer compensation is a policy of full consumer compensation, for any $\omega \in E \cup I$, which is exactly the definition of Nash equilibrium. As a result, $\forall p_{f t}^{*} \in\left(\bar{p}_{f t}, \bar{p}_{f t}^{c}\right)$ the equilibrium trade policy is given by $\mathbf{t}^{c} \equiv\left\{t^{c}, \ldots, t^{c}\right\}$ such that $p^{*}\left(t^{c}, \ldots, t^{c}, p_{f t}^{*}\right)-t^{c}=\bar{p} \forall \omega \in E \cup I$.

(ii) Full producer compensation policy. The proof of this second statement proceeds through the same logical steps as above and is thus omitted.

Proof of Proposition 4. (i) Policy complementarity. The reaction function of country $\omega$, $t_{\omega}\left(\mathbf{t}_{-\omega}\right)$, is implicitly given by

$$
t_{\omega}=p^{*}\left(t_{\omega}, \mathbf{t}_{-\omega}, p_{f t}^{*}\right)-\bar{p}
$$

where $\mathbf{t}_{-\omega} \equiv\left\{t_{1}, . ., t_{\omega-1}, t_{\omega+1}, . . t_{E+I}\right\}$. Define

$$
J\left(t_{\omega}, \mathbf{t}_{-\omega}\right) \equiv p^{*}\left(t_{\omega}, \mathbf{t}_{-\omega}, p_{f t}^{*}\right)-\bar{p}-t_{\omega} .
$$

Using the implicit function theorem, for any element $t_{-\omega} \in \mathbf{t}_{-\omega}$ we obtain

$$
\frac{d t_{\omega}}{d t_{-\omega}}=-\frac{\frac{d J}{d t_{-\omega}}}{\frac{d J}{d t_{\omega}}}=\frac{\frac{d p^{*}}{d t_{-\omega}}}{1-\frac{d p^{*}}{d t_{\omega}}} .
$$

To prove that $d t_{\omega} / d t_{-\omega} \in(0,1)$ we now show that $d p^{*} / d t_{\omega}=d p^{*} / d t_{-\omega} \in(0,1 /(E+I)$ ) (where $E+I \geqslant 2)$. The proof is simply a "discrete version" of the analogous result contained in Proposition 
2. Food market equilibrium is obtained when global export supply equalizes global import demand, $x\left(p^{*}-t_{\omega}\right)=m\left(p^{*}-t_{\omega}\right)$. Totally deriving the equilibrium condition, we can express $d p^{*} / d t_{\omega}$ as,

$$
\frac{d p^{*}}{d t_{\omega}}=\frac{\frac{d m}{d t_{\omega}}-\frac{d x}{d t_{\omega}}}{\frac{d x}{d p^{*}}-\frac{d m}{d p^{*}}} .
$$

The fact that $d m / d t, d x / d p^{*}>0$ and $d x / d t, d m / d p^{*}<0$ ensures that (20) is strictly positive. On the other hand, to prove that it is strictly lower than $1 /(E+I)$, recall that global export supply and global import demand of food can be disaggregated into

$$
\begin{aligned}
x\left(p^{*}-t_{\omega}\right) & \equiv E \cdot x_{E}\left(p^{*}-t_{\omega}\right)+(N-E) \cdot x_{(N-E)}\left(p^{*}\right), \\
m\left(p^{*}-t_{\omega}\right) & \equiv I \cdot m_{I}\left(p^{*}-t_{\omega}\right)+(M-I) \cdot m_{(M-I)}\left(p^{*}\right) .
\end{aligned}
$$

Deriving both expressions w.r.t. $p^{*}$, we obtain

$$
\begin{aligned}
& \frac{d x}{d p^{*}}=E \frac{d x_{E}}{d p^{*}}+(N-E) \frac{d x_{(N-E)}}{d p^{*}} \\
& \frac{d m}{d p^{*}}=I \frac{d m_{I}}{d p^{*}}+(M-I) \frac{d m_{(M-I)}}{d p^{*}} .
\end{aligned}
$$

Plugging the last two expressions into (20), the fact that (i) $d x_{E} / d p^{*}=-d x / d t_{\omega}, d m_{I} / d p^{*}=$ $-d m / d t_{\omega}$, coupled with the fact that (ii) $d x_{(N-E)} / d p^{*}>0, d m_{(M-I)} / d p^{*}<0$, guarantees that (20) is lower than $1 /(E+I)$.

(ii) The multiplier effect. From the reaction function of country $\omega,(19)$, we now want to show that the total derivative of $t_{\omega}$ with respect to $p_{f t}^{*}$ is greater than its partial derivative. It is

$$
\frac{\partial t_{\omega}}{\partial p_{f t}^{*}}=\frac{\partial p^{*}}{\partial p_{f t}^{*}}
$$

while

$$
\frac{d t_{\omega}}{d p_{f t}^{*}}=\frac{\partial p^{*}}{\partial p_{f t}^{*}}+\frac{d p^{*}}{d t_{\omega}} \frac{d t_{\omega}}{d p_{f t}^{*}}+\sum_{j \in(E \cup I \backslash \omega)} \frac{d p^{*}}{d t_{j}} \frac{d t_{j}}{d p_{f t}^{*}} .
$$

Given that the policy of compensating protectionism is identical across the whole set of $E+I$ countries, it is $d t_{\omega} / d p_{f t}^{*}=d t_{j} / d p_{f t}^{*}$ and $d p^{*} / d t_{\omega}=d p^{*} / d t_{j}$. Hence, from the last two equations we obtain

$$
\frac{d t_{\omega}}{d p_{f t}^{*}}=\Phi \frac{\partial t_{\omega}}{\partial p_{f t}^{*}} \forall \omega \in E \cup I
$$

where

$$
\Phi \equiv \frac{1}{1-(E+I) \frac{d p^{*}}{d t_{\omega}}},
$$

which is strictly greater than 1 given that $d p^{*} / d t_{\omega} \in(0,1 /(E+I))$.

Finally note that, when $E=N$ and $I=M$, it is immediate to verify from (20) that $d p^{*} / d t_{\omega}=$ $1 /(E+I)$, thus implying an infinite multiplier, $\Phi \rightarrow \infty$. 
Figure 1: International food prices 1990-2011

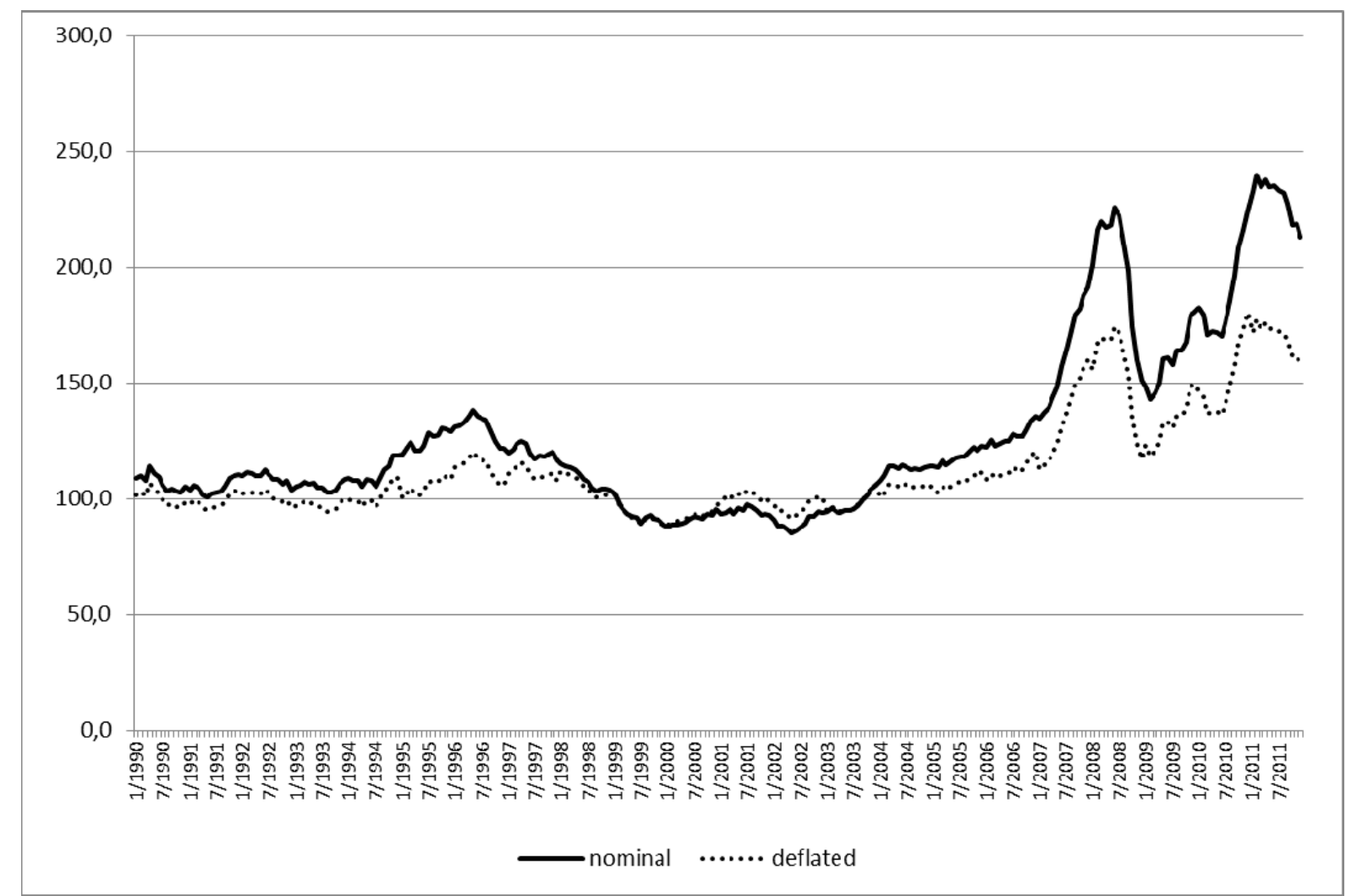

Note: The food price index is calculated as the average of five commodity group prices, meat, dairy, cereals, oils and fats and sugar, weighted by the export shares of each of the commodities. Nominal prices are deflated using the World Bank Manufacturing Unit Values.

Source: FAO commodity price statistics. 
Figure 2: International food prices and trade policy measures

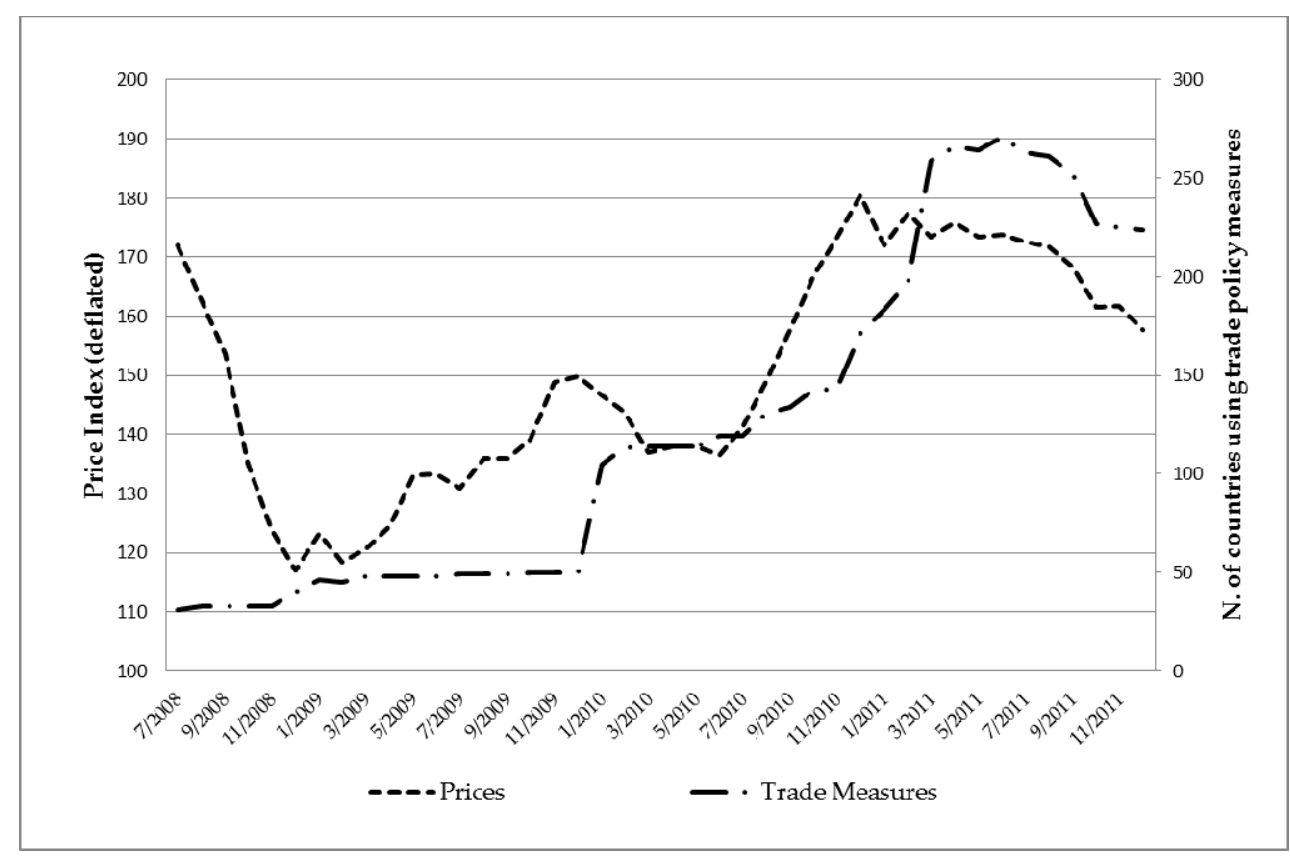

Source: Authors' calculations on FAO and IMF commodity price statistics and on WTO/GTA databases on trade policy measures. 
Figure 3: Trade policy (small economy)

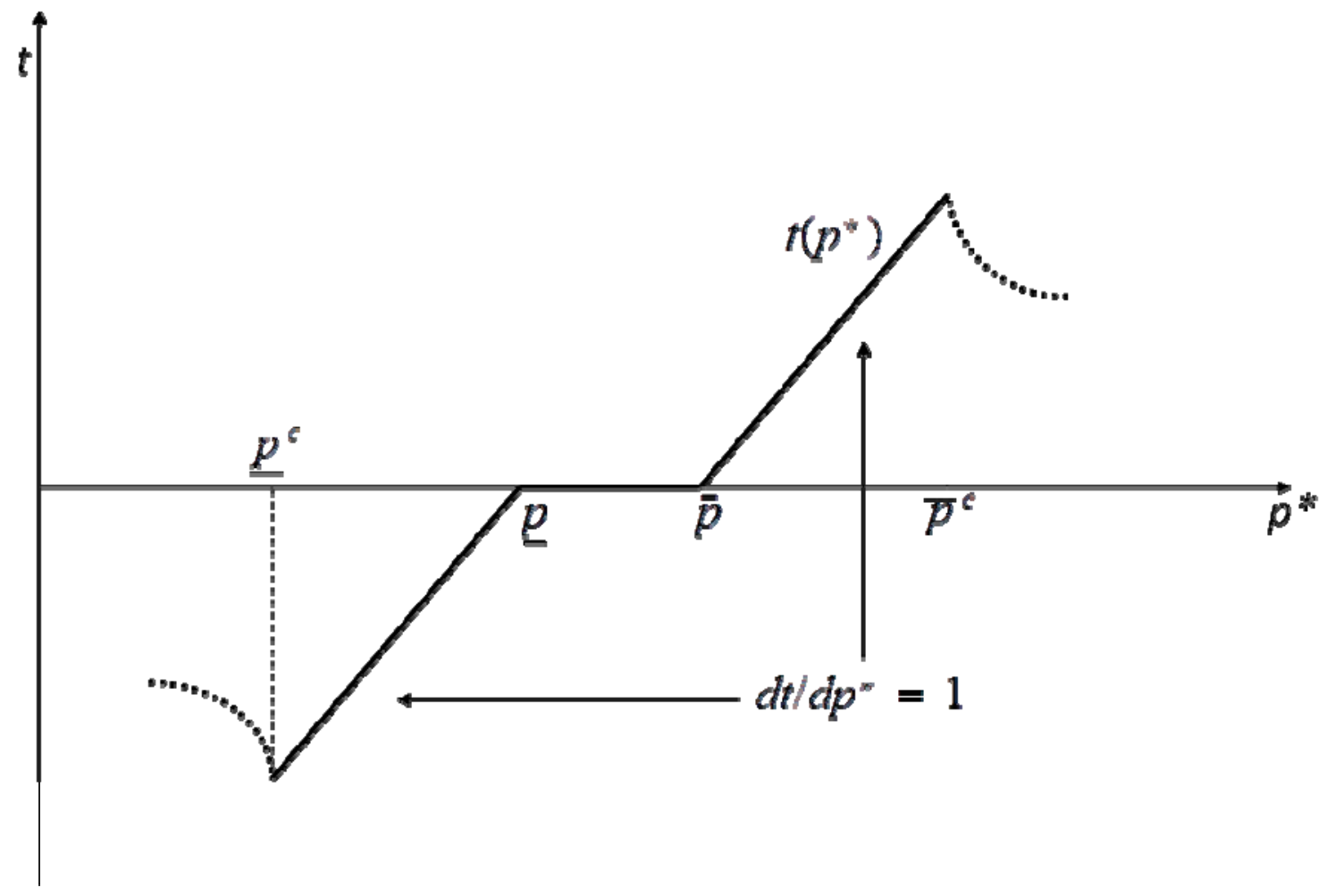

Figure 4: Multiplier effect (small economies)

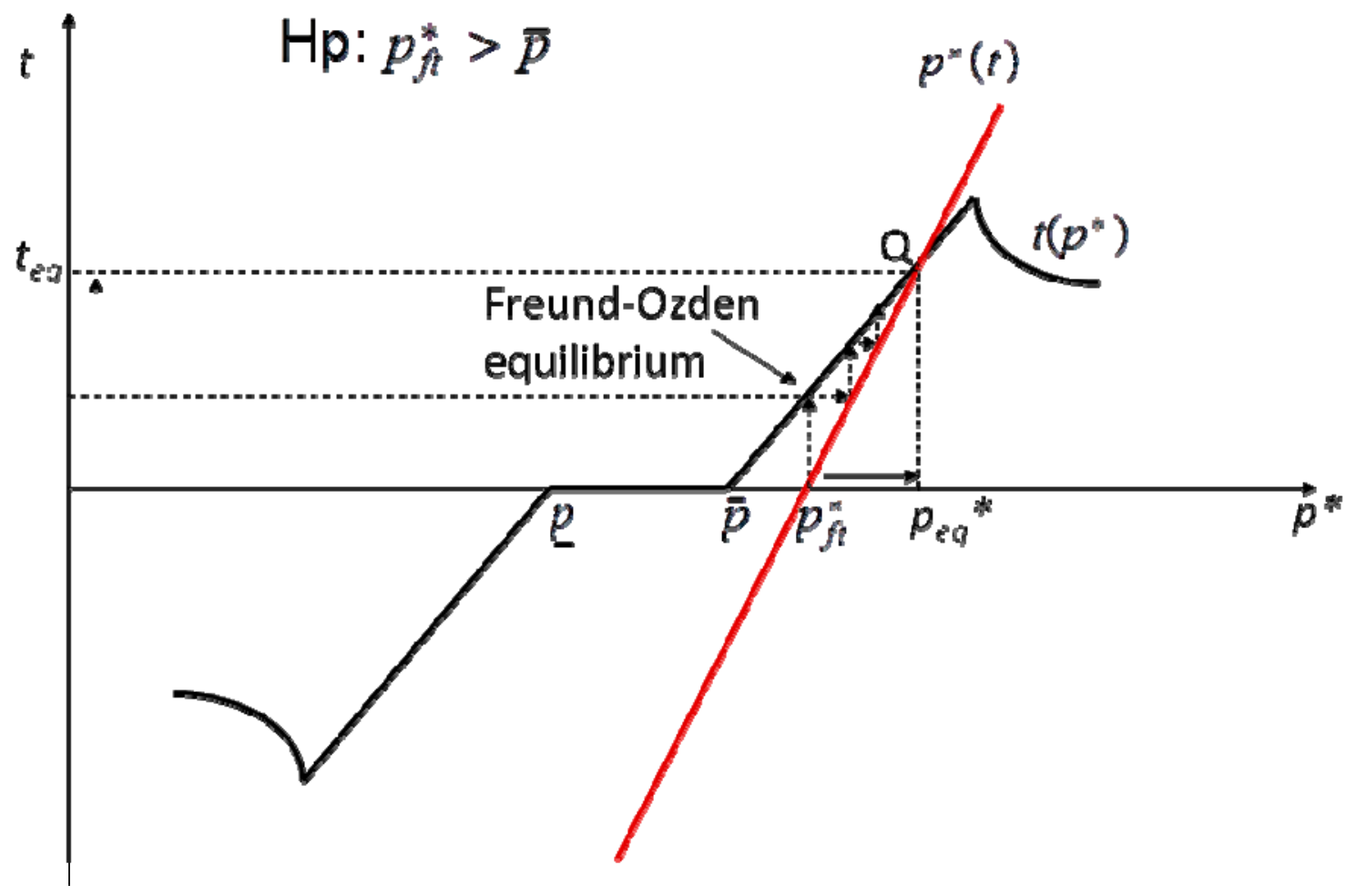


Figure 5: Multiplier effect (large economies)

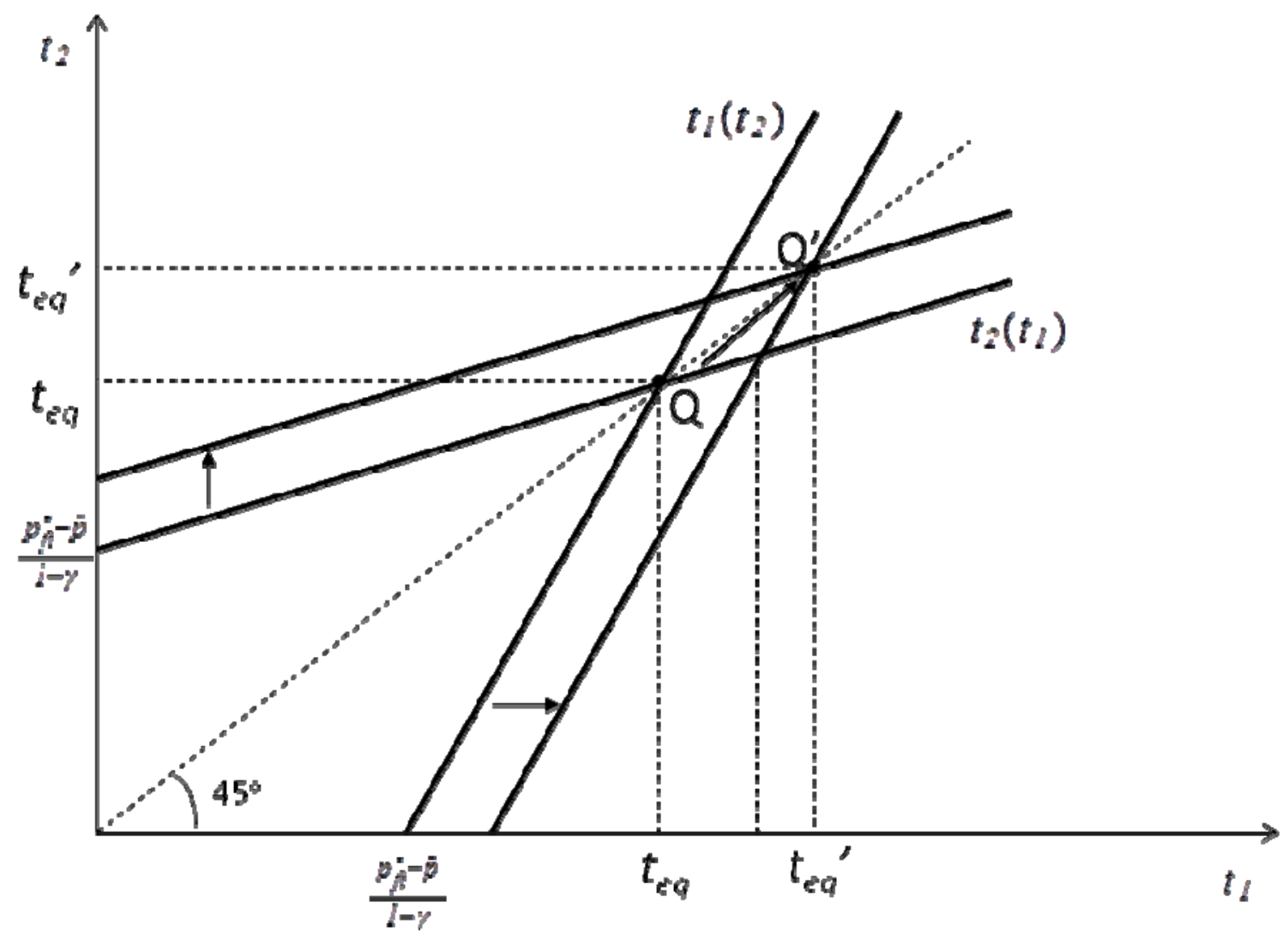

Table 1: International food prices before and after 2006

\begin{tabular}{|c|c|c|c|c|c|c|c|c|c|c|c|c|}
\hline & \multicolumn{2}{|c|}{ Food } & \multicolumn{2}{|c|}{ Meat } & \multicolumn{2}{|c|}{ Dairy } & \multicolumn{2}{|c|}{ Cereals } & \multicolumn{2}{|c|}{ Oils } & \multicolumn{2}{|c|}{ Sugar } \\
\hline & Mean & s.d. & Mean & s.d. & Mean & s.d. & Mean & s.d. & Mean & s.d. & Mean & s.d. \\
\hline $1990-2006$ & 108.62 & 12.87 & 115.09 & 14.36 & 100.03 & 18.19 & 102.42 & 14.79 & 98.91 & 21.08 & 139.51 & 38.65 \\
\hline World Food crisis 2007- mid-2008 & 179.78 & 31.82 & 138.55 & 14.09 & 229.52 & 42.05 & 194.90 & 50.38 & 205.12 & 54.67 & 154.82 & 18.82 \\
\hline World Food crisis mid-2008-2011 & 197.88 & 29.18 & 166.20 & 18.82 & 194.57 & 35.70 & 206.62 & 37.78 & 207.17 & 43.77 & 308.50 & 63.50 \\
\hline
\end{tabular}

Source: Authors' calculations on FAO commodity prices statistics. 
Table 2: Trade policy measures by product

\begin{tabular}{|c|c|c|c|c|}
\hline Hscode & Product Description & $\begin{array}{l}\text { Number of trade } \\
\text { measures }^{\mathrm{a}}\end{array}$ & $\begin{array}{c}\text { Number of } \\
\text { trade } \\
\text { measures } x \\
\text { time }^{b} \\
\end{array}$ & $\begin{array}{c}\text { \% Trade } \\
\text { covered by } \\
\text { trade measures }\end{array}$ \\
\hline 0803 & Bananas, excluding plantains & 1 & 9 & 0.00004 \\
\hline 1202 & Ground-nut, not roasted or otherwise cooked & 1 & 42 & 0.003 \\
\hline 0401 & milk and cream, not concentrated or sweetened & 4 & 95 & 0.26 \\
\hline 1504 & Fats and oils and their fractions & 3 & 52 & 0.27 \\
\hline 0204 & Meat of sheep or goats, fresh, chilled or frozen & 4 & 48 & 0.36 \\
\hline 0305 & Fish, dried, salted etc, smoked etc & 1 & 5 & 0.55 \\
\hline 1207 & Olive oil and its fractions & 2 & 28 & 0.67 \\
\hline 1509 & Other oil seeds and oleaginous fruits & 5 & 115 & 0.81 \\
\hline 0406 & Cheese and curd & 3 & 93 & 1.47 \\
\hline 0201 & Meat of bovine animals, fresh or chilled & 3 & 57 & 3.10 \\
\hline 1507 & Soya-bean oil and its fractions & 7 & 180 & 3.16 \\
\hline 1201 & Citrus fruit, fresh or dried & 5 & 87 & 3.37 \\
\hline 0805 & Soya beans, whether or not broken & 1 & 22 & 3.37 \\
\hline 0405 & Butter and other fats and oils derived from milk & 4 & 69 & 3.76 \\
\hline 1513 & Coconut, palm kernel or babassu oil & 8 & 187 & 4.03 \\
\hline 0901 & Coffee, whether or not roasted or decaffeinated & 2 & 40 & 4.62 \\
\hline 1508 & Ground-nut oil and its fractions & 4 & 78 & 5.29 \\
\hline 0304 & Fish fillets \& other fish meat, fresh, chill or frozen & 4 & 56 & 5.55 \\
\hline 1514 & Rape, colza or mustard oil and fractions & 6 & 131 & 5.75 \\
\hline 0306 & Crustaceans, live, fresh etc, and cooked etc. & 2 & 52 & 8.10 \\
\hline 1007 & Grain sorghum & 28 & 286 & 9.28 \\
\hline 0207 & Meat and edible offal, of the poultry of heading 0 & 7 & 141 & 9.34 \\
\hline 0203 & Meat of swine, fresh, chilled or frozen & 8 & 192 & 9.50 \\
\hline 1208 & Flours and meals of oil seeds or oleaginous fruits & 2 & 49 & 11.55 \\
\hline 1512 & Sunflower-seed, safflower or cotton-seed oil and fats & 6 & 138 & 28.15 \\
\hline 1006 & Rice & 6 & 154 & 35.72 \\
\hline 1005 & Maize (corn) & 36 & 437 & 38.16 \\
\hline 1701 & Cane or beet sugar and chemically pure sucrose & 32 & 403 & 51.08 \\
\hline 1003 & Barley & 33 & 735 & 53.17 \\
\hline 1511 & Palm oil and its fractions, whether or not refined & 9 & 192 & 55.23 \\
\hline 1801 & Cocoa beans, whole or broken, raw or roasted & 2 & 60 & 69.21 \\
\hline 1001 & Wheat and meslin & 42 & 986 & 73.85 \\
\hline
\end{tabular}

Note: a. Number of countries imposing at least one export restriction or import promotion measures over the time period 2008-2011, by product. b. Number of countries multiplied the number of periods (months) imposing at least one export restriction or import promotion measures over the time period 2008-2011, by product c. Calculated as the sum of countries imposing an export restriction or import promotion measures between 2008 and 2011 in a certain hs4 product, weighted by the average share of exports or imports of such product over the period 2000-2005.

Source: Authors' calculations on WTO and GTA databases on trade policy. 
Table 3: Summary statistics

\begin{tabular}{|c|c|c|c|c|c|c|}
\hline & \multicolumn{6}{|c|}{ Prices and trade policy measures 2008-2011 } \\
\hline & \multicolumn{3}{|c|}{ Full sample } & \multicolumn{3}{|c|}{ Staple food sample } \\
\hline & Mean & Sd & Obs. & Mean & Sd & Obs. \\
\hline Trade policy utilization (TPU) ${ }_{\mathrm{ikt}}$ & 0.045 & 0.208 & 114912 & 0.128 & 0.334 & 21798 \\
\hline Price changes from 3yrs moving average $k_{k, t-1}$ & 0.054 & 0.211 & 100968 & 0.065 & 0.227 & 19404 \\
\hline Price changes from 5yrs moving average $k, t-1$ & 0.091 & 0.205 & 100553 & 0.129 & 0.187 & 19404 \\
\hline Price changes from hist. (1980-2006) average $k, t-1$ & 0.115 & 0.351 & 87108 & 0.185 & 0.280 & 17682 \\
\hline Price changes from hist. (2000-2006) average $k, t-1$ & 0.527 & 0.505 & 100968 & 0.630 & 0.438 & 19404 \\
\hline \multirow[t]{4}{*}{ Global trade policy -i,kt-1 (weighted) } & 0.080 & 0.153 & 114114 & 0.166 & 0.203 & 21630 \\
\hline & \multicolumn{6}{|c|}{ Instruments 2008-2011 } \\
\hline & \multicolumn{3}{|c|}{ Full sample } & \multicolumn{3}{|c|}{ Staple food sample } \\
\hline & Mean & Sd & Obs. & Mean & $\mathrm{Sd}$ & Obs. \\
\hline $\log$ Rainfall top3 producers k,t-1 & 9.383 & 2.228 & 73080 & 9.864 & 2.070 & 21798 \\
\hline Rainfall variation top3 producers k,t-1 & 2.380 & 0.712 & 73080 & 2.418 & 0.668 & 21798 \\
\hline Elections top 3 traders $\mathrm{k}, \mathrm{t}-1$ & 0.061 & 0.240 & 114912 & 0.032 & 0.175 & 19620 \\
\hline \multirow[t]{4}{*}{ Number of trade measures (hs2) -k,t-1-1} & 14.173 & 23.335 & 114912 & 25.982 & 37.230 & 21798 \\
\hline & \multicolumn{6}{|c|}{ Control variables } \\
\hline & \multicolumn{3}{|c|}{ Full sample } & \multicolumn{3}{|c|}{ Staple food sample } \\
\hline & Mean & Sd & Obs. & Mean & Sd & Obs. \\
\hline $\log$ Trade $_{i, k, t-1}$ & 12.862 & 4.787 & 112569 & 14.649 & 4.121 & 21471 \\
\hline log GDP per capita i (2000-2005) & 8.817 & 1.387 & 114912 & 8.568 & 1.299 & 21798 \\
\hline Production Share $k_{\text {(2005) }}$ & 0.040 & 0.061 & 44982 & 0.026 & 0.052 & 21798 \\
\hline
\end{tabular}


Table 4: Determinants of trade policy utilization (full sample)

\begin{tabular}{|c|c|c|c|c|c|c|c|c|c|}
\hline & Logit & LPM & LPM & Logit & LPM & LPM & Logit & LPM & LPM \\
\hline & $(1)$ & $(2)$ & (3) & $(4)$ & (5) & $(6)$ & (7) & (8) & (9) \\
\hline \multicolumn{10}{|c|}{ Price changes from 3yrs moving average k,t- } \\
\hline \multirow[t]{2}{*}{1} & $0.0108^{* * *}$ & $0.0700^{* * *}$ & $0.0704^{* * *}$ & $0.0141^{* *}$ & $0.0989^{* * *}$ & $0.0989^{* * *}$ & 0.0055 & $0.0514^{* * *}$ & $0.0499^{* * *}$ \\
\hline & {$[0.003]$} & {$[0.010]$} & [0.011] & [0.007] & {$[0.021]$} & {$[0.021]$} & [0.007] & {$[0.014]$} & [0.014] \\
\hline \multirow[t]{2}{*}{$\log$ Trade $_{i, k, t-1}$} & $0.0027^{* * *}$ & $0.0053^{* * *}$ & $0.0023^{* * *}$ & $0.0035^{* * *}$ & $0.0045^{* * *}$ & 0.0005 & $0.0037^{* * *}$ & $0.0045^{* * *}$ & 0.0002 \\
\hline & {$[0.000]$} & {$[0.000]$} & {$[0.000]$} & {$[0.000]$} & {$[0.000]$} & {$[0.001]$} & {$[0.000]$} & {$[0.000]$} & {$[0.001]$} \\
\hline \multirow[t]{2}{*}{ log GDP per capita i ( 2000-2005) } & $-0.0038^{* * *}$ & $-0.0086^{* * *}$ & & -0.0014 & -0.0025 & & -0.0012 & -0.0024 & \\
\hline & {$[0.001]$} & {$[0.001]$} & & {$[0.001]$} & {$[0.002]$} & & {$[0.001]$} & {$[0.002]$} & \\
\hline \multirow[t]{2}{*}{ Production Share i,k (2005) } & & & & $0.0662^{* * *}$ & $0.1637^{* * *}$ & $0.1993^{* * *}$ & $0.0616^{* * *}$ & $0.1471^{* * *}$ & $0.1753^{* * *}$ \\
\hline & & & & {$[0.012]$} & {$[0.032]$} & {$[0.032]$} & {$[0.013]$} & {$[0.032]$} & {$[0.032]$} \\
\hline \multirow[t]{2}{*}{ Global trade policy $-\mathrm{i}, \mathrm{k}, \mathrm{t}-\mathrm{1}$ (weighted) } & & & & & & & $0.0494^{* * *}$ & $0.5716^{* * *}$ & $0.5933^{* * *}$ \\
\hline & & & & & & & {$[0.013]$} & {$[0.039]$} & {$[0.039]$} \\
\hline Time (monthly) FE & Yes & Yes & Yes & Yes & Yes & Yes & Yes & Yes & Yes \\
\hline Product FE & Yes & Yes & Yes & Yes & Yes & Yes & Yes & Yes & Yes \\
\hline Year FE & Yes & Yes & Yes & Yes & Yes & Yes & Yes & Yes & Yes \\
\hline Country FE & & & Yes & & & Yes & & & Yes \\
\hline Observations & 95494 & 98909 & 98909 & 40518 & 41782 & 41782 & 40096 & 41360 & 41360 \\
\hline R-squared & & 0.121 & 0.189 & & 0.171 & 0.248 & & 0.205 & 0.286 \\
\hline
\end{tabular}

Note: Standard errors clustered at product-time level. ${ }^{* *} \mathrm{p}<0.01,{ }^{* *} \mathrm{p}<0.05,{ }^{*} \mathrm{p}<0.1$. 
Table 5: Determinants of trade policy utilization: staple food products

\begin{tabular}{|c|c|c|c|c|c|c|}
\hline & Logit & LPM & LPM & Logit & LPM & LPM \\
\hline & (1) & (2) & (3) & (4) & (5) & (6) \\
\hline \multirow[t]{2}{*}{ Price changes from 3yrs moving average $k, t-1$} & $0.0637^{* * *}$ & $0.1926^{* * *}$ & $0.1953^{* * *}$ & $0.0531^{* * *}$ & $0.1332^{* * *}$ & $0.1340^{* * *}$ \\
\hline & {$[0.020]$} & {$[0.030]$} & {$[0.030]$} & {$[0.020]$} & {$[0.023]$} & {$[0.023]$} \\
\hline \multirow[t]{2}{*}{$\log$ Trade $_{i, k, t-1}$} & $0.0052^{* * *}$ & $0.0053^{* * *}$ & $0.0040^{* * *}$ & $0.0051^{* * *}$ & $0.0051^{* * *}$ & $0.0030^{* * *}$ \\
\hline & {$[0.001]$} & {$[0.001]$} & {$[0.001]$} & [0.001] & [0.001] & [0.001] \\
\hline \multirow[t]{2}{*}{ log GDP per capita i (2000-2005) } & $0.0059 * *$ & $0.0114^{* *}$ & & $0.0065^{* *}$ & $0.0116^{* *}$ & \\
\hline & {$[0.003]$} & {$[0.005]$} & & [0.003] & {$[0.005]$} & \\
\hline \multirow[t]{2}{*}{ Production Share i,k (2005) } & $0.3036^{* * *}$ & $0.5941^{* * *}$ & $0.6472^{* * *}$ & $0.2832^{* * *}$ & $0.5554^{* * *}$ & $0.6055^{* * *}$ \\
\hline & {$[0.040]$} & {$[0.076]$} & {$[0.055]$} & {$[0.038]$} & {$[0.076]$} & {$[0.056]$} \\
\hline \multirow[t]{2}{*}{ Global trade policy -i,k,t-1-1 (weighted) } & & & & $0.0718^{* *}$ & $0.5319^{* * *}$ & $0.5613^{* * *}$ \\
\hline & & & & {$[0.030]$} & {$[0.045]$} & {$[0.045]$} \\
\hline Time (monthly) FE & Yes & Yes & Yes & Yes & Yes & Yes \\
\hline Product FE & Yes & Yes & Yes & Yes & Yes & Yes \\
\hline Year FE & Yes & Yes & Yes & Yes & Yes & Yes \\
\hline Country FE & & & Yes & & & Yes \\
\hline Observations & 19103 & 19103 & 19103 & 18954 & 18954 & 18954 \\
\hline R-squared & & 0.215 & 0.362 & & 0.24 & 0.391 \\
\hline
\end{tabular}


Table 6: Determinants of trade policy utilization: large traders

\begin{tabular}{|c|c|c|c|c|c|c|c|c|}
\hline & $\begin{array}{l}\text { All food } \\
\text { products }\end{array}$ & $\begin{array}{l}\text { All food } \\
\text { products }\end{array}$ & $\begin{array}{c}\text { Staple } \\
\text { products }\end{array}$ & $\begin{array}{c}\text { Staple } \\
\text { products }\end{array}$ & $\begin{array}{l}\text { All food } \\
\text { products }\end{array}$ & $\begin{array}{l}\text { All food } \\
\text { products }\end{array}$ & $\begin{array}{c}\text { Staple } \\
\text { products }\end{array}$ & $\begin{array}{c}\text { Staple } \\
\text { products }\end{array}$ \\
\hline & (1) & (2) & (3) & (4) & (5) & (6) & (7) & (8) \\
\hline \multirow[t]{2}{*}{ Price changes from 3yrs moving average $k, t-1$} & $0.0409^{* * *}$ & $0.0440^{* * *}$ & $0.1272^{* * *}$ & $0.1293^{* * *}$ & $0.0410^{* * *}$ & $0.0417^{* * *}$ & $0.1320^{* * *}$ & $0.1316^{* * *}$ \\
\hline & {$[0.015]$} & {$[0.015]$} & {$[0.024]$} & {$[0.024]$} & {$[0.015]$} & [0.015] & {$[0.024]$} & {$[0.024]$} \\
\hline \multirow{2}{*}{ Global trade policy -i,k,t-1-1 (weighted) } & $0.5711^{* * *}$ & $0.5473^{* * *}$ & $0.5311^{* * *}$ & $0.5124^{* * *}$ & $0.5748^{* * *}$ & $0.4785^{* * *}$ & $0.5404^{* * *}$ & $0.4435^{* * *}$ \\
\hline & {$[0.039]$} & {$[0.040]$} & {$[0.045]$} & {$[0.045]$} & {$[0.039]$} & {$[0.037]$} & {$[0.045]$} & {$[0.043]$} \\
\hline \multirow[t]{2}{*}{ Large importer } & 0.0008 & $-0.0112^{* *}$ & $-0.0126^{* * *}$ & $-0.0276^{* * *}$ & & & & \\
\hline & {$[0.004]$} & [0.005] & {$[0.004]$} & [0.006] & & & & \\
\hline \multirow[t]{2}{*}{$\begin{array}{l}\text { Price changes from 3yrs moving average } k, t-1 \times \text { Large } \\
\text { importer }\end{array}$} & $0.0434^{* * *}$ & $0.0287^{* *}$ & 0.0218 & 0.0105 & & & & \\
\hline & {$[0.013]$} & {$[0.013]$} & {$[0.015]$} & {$[0.015]$} & & & & \\
\hline \multirow[t]{2}{*}{ Global trade policy $-\mathrm{i}, \mathrm{k}, \mathrm{t}-1$ (weighted $) \times$ Large importer } & & $0.1012^{* * *}$ & & $0.0814^{* * *}$ & & & & \\
\hline & & {$[0.023]$} & & {$[0.022]$} & & & & \\
\hline \multirow[t]{2}{*}{ Large exporter } & & & & & $0.0418^{* * *}$ & 0.0047 & $0.0775^{* * *}$ & $0.0160^{* * *}$ \\
\hline & & & & & {$[0.003]$} & [0.003] & {$[0.005]$} & {$[0.005]$} \\
\hline \multirow{2}{*}{$\begin{array}{l}\text { Price changes from 3yrs moving average } k, t-1 \times \text { Large } \\
\text { exporter }\end{array}$} & & & & & & & & \\
\hline & & & & & $\begin{array}{c}0.0425^{* * x} \\
{[0.014]}\end{array}$ & $\begin{array}{c}0.0356^{* \star *} \\
{[0.014]}\end{array}$ & $\begin{array}{l}0.0055 \\
{[0.017]}\end{array}$ & $\begin{array}{l}0.0011 \\
{[0.017]}\end{array}$ \\
\hline \multirow[t]{2}{*}{ Global trade policy $-i, k, t-1$ (weighted) $\times$ Large exporter } & & & & & & $0.3219^{* * *}$ & & $0.3285^{* * *}$ \\
\hline & & & & & & {$[0.020]$} & & {$[0.017]$} \\
\hline Observations & 41360 & 41360 & 18954 & 18954 & 41360 & 41360 & 18954 & 18954 \\
\hline R-squared & 0.205 & 0.206 & 0.241 & 0.241 & 0.209 & 0.217 & 0.249 & 0.257 \\
\hline
\end{tabular}

Note: Standard errors clustered at product-time level. ${ }^{* *} \mathrm{p}<0.01,{ }^{* *} \mathrm{p}<0.05,{ }^{*} \mathrm{p}<0.1$. Other control variables included in the regression are GDP per capita, log Trade, Production shares and time (month), year and product FE. 
Table 7: Determinants of trade policy utilization: Instrumental Variables

\begin{tabular}{|c|c|c|c|c|c|c|c|c|c|}
\hline & $\begin{array}{c}\text { All } \\
\text { countries }\end{array}$ & $\begin{array}{c}\text { Large } \\
\text { exporters }\end{array}$ & $\begin{array}{c}\text { Large } \\
\text { importers }\end{array}$ & $\begin{array}{c}\text { All } \\
\text { countries }\end{array}$ & $\begin{array}{c}\text { All } \\
\text { countries }\end{array}$ & $\begin{array}{c}\text { Large } \\
\text { importers }\end{array}$ & $\begin{array}{c}\text { Large } \\
\text { importers }\end{array}$ & $\begin{array}{c}\text { Large } \\
\text { exporters }\end{array}$ & $\begin{array}{c}\text { Large } \\
\text { exporters }\end{array}$ \\
\hline & LPM & LPM & LPM & 2SLS & 2SLS & 2SLS & 2SLS & 2SLS & 2SLS \\
\hline & $(1)$ & $(2)$ & (3) & $(4)$ & $(5)$ & $(6)$ & $(7)$ & $(8)$ & $(9)$ \\
\hline \multirow[t]{2}{*}{ Price changes from 3yrs moving average $k, t-1$} & $0.1051^{* * *}$ & $0.0669^{* *}$ & $0.1803^{* * *}$ & $0.4642^{* * *}$ & $0.4707^{* * *}$ & $0.3939^{* * *}$ & $0.4029^{* * *}$ & $0.6043^{* * *}$ & $0.5972^{* * *}$ \\
\hline & {$[0.032]$} & {$[0.034]$} & [0.042] & {$[0.074]$} & {$[0.075]$} & {$[0.080]$} & {$[0.080]$} & {$[0.075]$} & [0.075] \\
\hline \multirow[t]{2}{*}{ Global trade policy -i,k,t-1 (weighted) } & $0.5950^{* * *}$ & $0.7053^{* * *}$ & $0.7132^{* * *}$ & $0.5983^{* * *}$ & $0.5965^{* * *}$ & $0.5081^{* * *}$ & $0.5114^{* * *}$ & $0.6059^{* * *}$ & $0.6067^{* * *}$ \\
\hline & {$[0.046]$} & {$[0.045]$} & {$[0.057]$} & {$[0.181]$} & {$[0.182]$} & [0.167] & {$[0.168]$} & {$[0.201]$} & {$[0.202]$} \\
\hline Time (monthly) FE & Yes & Yes & Yes & Yes & Yes & Yes & Yes & Yes & Yes \\
\hline Year FE & Yes & Yes & Yes & Yes & Yes & Yes & Yes & Yes & Yes \\
\hline Product FE & Yes & Yes & Yes & Yes & Yes & Yes & Yes & Yes & Yes \\
\hline Country FE & Yes & Yes & Yes & & Yes & & Yes & & Yes \\
\hline Observations & 16976 & 4606 & 5308 & 16976 & 16976 & 4606 & 4606 & 5308 & 5308 \\
\hline Hansen J statistic & & & & 2.681 & 2.685 & 2.72 & 3.634 & 1.499 & 0.139 \\
\hline p-value of Hansen J statistic & & & & 0.262 & 0.261 & 0.257 & 0.163 & 0.473 & 0.933 \\
\hline
\end{tabular}

Note: Standard errors clustered at product-time level. ${ }^{* * *} \mathrm{p}<0.01,{ }^{* *} \mathrm{p}<0.05,{ }^{*} \mathrm{p}<0.1$. Other control variables included in the regression are GDP per capita, log Trade and Production shares. 
Table 8: The impact of trade policy utilization on international prices

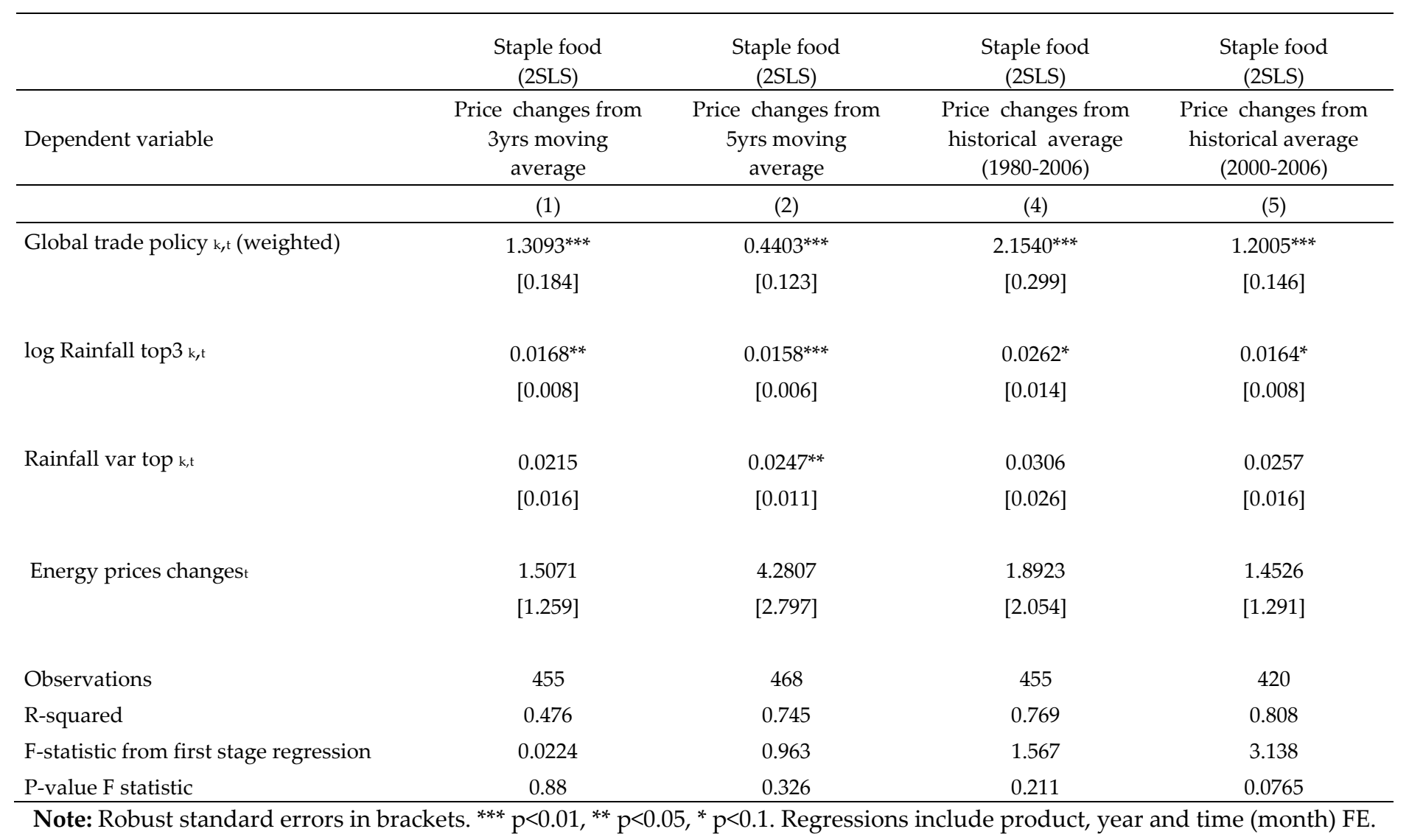


Appendix Table 1: Determinants of trade policy utilization (lagged explanatory variables)

\begin{tabular}{|c|c|c|c|c|c|c|c|c|}
\hline & $\begin{array}{l}\text { All food } \\
\text { products }\end{array}$ & $\begin{array}{l}\text { All food } \\
\text { products }\end{array}$ & $\begin{array}{l}\text { Staple } \\
\text { products }\end{array}$ & $\begin{array}{l}\text { Staple } \\
\text { products }\end{array}$ & $\begin{array}{l}\text { All food } \\
\text { products }\end{array}$ & $\begin{array}{l}\text { All food } \\
\text { products }\end{array}$ & $\begin{array}{c}\text { Staple } \\
\text { products }\end{array}$ & $\begin{array}{c}\text { Staple } \\
\text { products }\end{array}$ \\
\hline & $(1)$ & $(2)$ & (3) & (4) & $(5)$ & $(6)$ & $(7)$ & (8) \\
\hline \multirow[t]{2}{*}{ Price changes from 3yrs moving average $k, t-2$} & $0.0280^{*}$ & $0.0269^{*}$ & $0.1223^{* * *}$ & $0.1213^{* * *}$ & & & & \\
\hline & {$[0.016]$} & {$[0.016]$} & [0.029] & [0.029] & & & & \\
\hline \multirow[t]{2}{*}{ Global trade policy -i,k,t-2 (weighted) } & $0.6577^{* * *}$ & $0.6857^{* * *}$ & $0.5859^{* * *}$ & $0.6218^{* * *}$ & & & & \\
\hline & {$[0.055]$} & {$[0.054]$} & [0.064] & {$[0.064]$} & & & & \\
\hline \multirow[t]{2}{*}{ Price changes from 3yrs moving average $k, t-3$} & & & & & 0.016 & 0.0151 & $0.1167^{* * *}$ & $0.1155^{* * *}$ \\
\hline & & & & & [0.017] & [0.017] & {$[0.030]$} & {$[0.031]$} \\
\hline Global trade policy -i,k,t-3 (weighted) & & & & & $0.5837^{* * *}$ & $0.6110^{* * *}$ & $0.4838^{* * *}$ & $0.5184^{* * *}$ \\
\hline Time (monthly) FE & Yes & Yes & Yes & Yes & Yes & Yes & Yes & Yes \\
\hline Product FE & Yes & Yes & Yes & Yes & Yes & Yes & Yes & Yes \\
\hline Year FE & Yes & Yes & Yes & Yes & Yes & Yes & Yes & Yes \\
\hline Country FE & & Yes & & Yes & & Yes & & Yes \\
\hline Observations & 41360 & 41360 & 18954 & 18954 & 41360 & 41360 & 18954 & 18954 \\
\hline R-squared & 0.197 & 0.277 & 0.232 & 0.383 & 0.191 & 0.271 & 0.226 & 0.375 \\
\hline
\end{tabular}


Appendix Table 2: Determinants of trade policy utilization (lagged explanatory variables, large traders)

\begin{tabular}{|c|c|c|c|c|c|c|c|c|}
\hline & $\begin{array}{l}\text { All food } \\
\text { products }\end{array}$ & $\begin{array}{c}\text { Staple } \\
\text { products }\end{array}$ & $\begin{array}{l}\text { All food } \\
\text { products }\end{array}$ & $\begin{array}{c}\text { Staple } \\
\text { products }\end{array}$ & $\begin{array}{l}\text { All food } \\
\text { products }\end{array}$ & $\begin{array}{c}\text { Staple } \\
\text { products }\end{array}$ & $\begin{array}{l}\text { All food } \\
\text { products }\end{array}$ & $\begin{array}{c}\text { Staple } \\
\text { products }\end{array}$ \\
\hline & \multicolumn{4}{|c|}{ Two lags $(x=2)$} & \multicolumn{4}{|c|}{ Three lags $(x=3)$} \\
\hline & $(1)$ & $(2)$ & $(3)$ & $(4)$ & $(5)$ & $(6)$ & $(7)$ & $(8)$ \\
\hline \multirow[t]{2}{*}{ Price changes from 3yrs moving average $k, t-x$} & 0.0185 & $0.1101^{* * *}$ & 0.0191 & $0.1082^{* * *}$ & 0.0065 & $0.1036^{* * *}$ & 0.0092 & $0.1060^{* * *}$ \\
\hline & {$[0.017]$} & {$[0.030]$} & {$[0.015]$} & {$[0.028]$} & {$[0.017]$} & {$[0.031]$} & {$[0.015]$} & {$[0.029]$} \\
\hline \multirow[t]{2}{*}{ Global trade policy -i,k,t-x (weighted) } & $0.6239^{* * *}$ & $0.5643^{* * *}$ & $0.5426^{* * *}$ & $0.4768^{* * *}$ & $0.5504^{* * *}$ & $0.4623^{* * *}$ & $0.4701^{* * *}$ & $0.3777^{* * *}$ \\
\hline & [0.056] & {$[0.064]$} & [0.052] & {$[0.061]$} & {$[0.058]$} & {$[0.066]$} & {$[0.054]$} & {$[0.063]$} \\
\hline \multirow[t]{2}{*}{ Large importer } & $-0.0144^{* * *}$ & $-0.0234^{* * *}$ & & & $-0.0140^{* * *}$ & $-0.0235^{* * *}$ & & \\
\hline & {$[0.004]$} & [0.005] & & & {$[0.004]$} & [0.005] & & \\
\hline \multirow[t]{2}{*}{ Price changes from 3yrs moving average $k, t-x \times$ Large importer } & $0.0375^{* * *}$ & $0.0399^{* * *}$ & & & $0.0374^{* * *}$ & $0.0438^{* * *}$ & & \\
\hline & [0.012] & {$[0.014]$} & & & {$[0.012]$} & {$[0.013]$} & & \\
\hline \multirow[t]{2}{*}{ 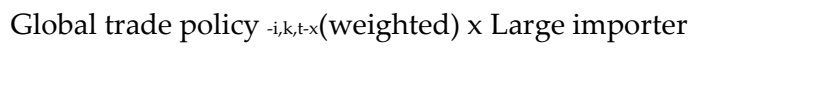 } & $0.1350^{* * *}$ & $0.0914^{* * *}$ & & & $0.1338^{* * *}$ & $0.0904^{* * *}$ & & \\
\hline & {$[0.029]$} & {$[0.028]$} & & & {$[0.029]$} & {$[0.028]$} & & \\
\hline \multirow[t]{2}{*}{ Large exporter } & & & 0.0009 & $0.0150^{* * *}$ & & & 0.0025 & $0.0182^{* * *}$ \\
\hline & & & {$[0.003]$} & [0.005] & & & {$[0.003]$} & {$[0.005]$} \\
\hline \multirow[t]{2}{*}{ Price changes from 3yrs moving average $k, t-x \times$ Large exporter } & & & $0.0271^{* * *}$ & $0.0407^{* * *}$ & & & $0.0208^{*}$ & $0.0304^{* *}$ \\
\hline & & & {$[0.010]$} & {$[0.013]$} & & & {$[0.011]$} & {$[0.014]$} \\
\hline \multirow[t]{2}{*}{ Global trade policy -i,k,t-x (weighted) $x$ Large exporter } & & & $0.3915^{* * *}$ & $0.4063^{* * *}$ & & & $0.3862^{* * *}$ & $0.3958^{* * *}$ \\
\hline & & & {$[0.025]$} & {$[0.024]$} & & & {$[0.026]$} & {$[0.025]$} \\
\hline Observations & 41360 & 18954 & 41360 & 18954 & 41360 & 18954 & 41360 & 18954 \\
\hline R-squared & 0.198 & 0.231 & 0.208 & 0.248 & 0.192 & 0.225 & 0.202 & 0.241 \\
\hline
\end{tabular}

Note: Standard errors clustered at product-time level. ${ }^{* * *} \mathrm{p}<0.01,{ }^{* *} \mathrm{p}<0.05,{ }^{*} \mathrm{p}<0.1$. Other control variables included in the regression are GDP per capita, $\log$ Trade, Production shares and product, time (month) and year FE. 
Appendix Table 3: Determinants of trade policy utilization (first stage results)

\begin{tabular}{|c|c|c|c|c|c|c|}
\hline & All & All & $\begin{array}{c}\text { Large } \\
\text { importers }\end{array}$ & $\begin{array}{c}\text { Large } \\
\text { importers }\end{array}$ & $\begin{array}{c}\text { Large } \\
\text { exporters }\end{array}$ & $\begin{array}{c}\text { Large } \\
\text { exporters }\end{array}$ \\
\hline & $(1)$ & (2) & (3) & (4) & (5) & (6) \\
\hline Dependent Variable & \multicolumn{6}{|c|}{ Price changes from 3yrs moving average $k, t-1$} \\
\hline $\log$ Rainfall top3 $\mathrm{k}, \mathrm{t}-1$ & $\begin{array}{c}0.0873^{* * *} \\
{[0.001]}\end{array}$ & $\begin{array}{c}0.0873^{* * *} \\
{[0.001]}\end{array}$ & $\begin{array}{c}0.0874^{* * *} \\
{[0.003]}\end{array}$ & $\begin{array}{c}0.0874^{* * *} \\
{[0.003]}\end{array}$ & $\begin{array}{c}0.0864^{* * *} \\
{[0.002]}\end{array}$ & $\begin{array}{c}0.0865^{* * *} \\
{[0.002]}\end{array}$ \\
\hline Rainfall var top3 $\mathrm{k,t-1}$ & $\begin{array}{c}0.0336^{* * *} \\
{[0.002]}\end{array}$ & $\begin{array}{c}0.0336^{* * *} \\
{[0.002]}\end{array}$ & $\begin{array}{c}0.0370^{* * *} \\
{[0.003]}\end{array}$ & $\begin{array}{c}0.0370^{* * *} \\
{[0.003]}\end{array}$ & $\begin{array}{c}0.0326^{* * *} \\
{[0.005]}\end{array}$ & $\begin{array}{c}0.0326^{* * *} \\
{[0.005]}\end{array}$ \\
\hline F-statistic & 62.7 & 62.4 & 56.61 & 56.14 & 67.79 & 67.52 \\
\hline Dependent Variable & \multicolumn{6}{|c|}{ Global trade policy -i,k, t-1 (weighted) } \\
\hline Number of measures (hs2) ${ }_{i,-k, t-1}$ & $\begin{array}{l}0.0017^{* * *} \\
{[0.000]}\end{array}$ & $\begin{array}{l}0.0017^{* * *} \\
{[0.000]}\end{array}$ & $\begin{array}{l}0.0018^{* * *} \\
{[0.000]}\end{array}$ & $\begin{array}{l}0.0018^{* * *} \\
{[0.000]}\end{array}$ & $\begin{array}{l}0.0016^{* * *} \\
{[0.000]}\end{array}$ & $\begin{array}{l}0.0016^{* * *} \\
{[0.000]}\end{array}$ \\
\hline Elections top3 traders $k, t-1$ & $\begin{array}{l}-0.1083^{* * *} \\
{[0.026]}\end{array}$ & $\begin{array}{l}-0.1080^{* * *} \\
{[0.026]}\end{array}$ & $\begin{array}{l}-0.0919^{* * *} \\
{[0.023]}\end{array}$ & $\begin{array}{l}-0.0919^{* * *} \\
{[0.023]}\end{array}$ & $\begin{array}{l}-0.1186^{* * *} \\
{[0.027]}\end{array}$ & $\begin{array}{l}-0.1179^{* * *} \\
{[0.027]}\end{array}$ \\
\hline F-statistic & 10.38 & 10.32 & 10.91 & 10.83 & 10.45 & 10.2 \\
\hline Observations & 16976 & 16976 & 4606 & 4606 & 5308 & 5308 \\
\hline
\end{tabular}

Note: Standard errors clustered at product-time level. ${ }^{* * *} \mathrm{p}<0.01,{ }^{* *} \mathrm{p}<0.05,{ }^{*} \mathrm{p}<0.1$. Other control variables included in the regression are GDP per capita, log Trade, Production shares and product, time (month) and year FE. Columns (2), (4) and (6) also include country fixed effects. 